\title{
Distribution and Associated Factors of Hepatic Iron- A Population-Based Imaging Study
}

\author{
Lisa Maier 1,2,3 ${ }^{(D)}$, Ricarda von Krüchten ${ }^{4}\left(\mathbb{D}\right.$, Roberto Lorbeer ${ }^{5,6}$, Jule Filler ${ }^{1,2,3} \mathbb{D}^{\mathbb{D}}$, Johanna Nattenmüller ${ }^{4,7}$, \\ Barbara Thorand 1,8 ${ }^{\mathbb{D}}$, Wolfgang Koenig ${ }^{6,9,10}$, Wolfgang Rathmann ${ }^{8,11}$, Fabian Bamberg ${ }^{4}$, Christopher L. Schlett 4 , \\ Annette Peters $1,2,6,8$ and Susanne Rospleszcz $1,2,6, *$ (D)
}

check for updates

Citation: Maier, L.; von Krüchten, R.; Lorbeer, R.; Filler, J.; Nattenmüller, J.; Thorand, B.; Koenig, W.; Rathmann, W.; Bamberg, F.; Schlett, C.L.; et al. Distribution and Associated Factors of Hepatic Iron-A Population-Based Imaging Study. Metabolites 2021, 11, 871. https://doi.org/10.3390/ metabo11120871

Academic Editors: Jeanine J. Prompers and Martin Krššák

Received: 1 December 2021

Accepted: 11 December 2021

Published: 15 December 2021

Publisher's Note: MDPI stays neutral with regard to jurisdictional claims in published maps and institutional affiliations.

Copyright: (c) 2021 by the authors. Licensee MDPI, Basel, Switzerland. This article is an open access article distributed under the terms and conditions of the Creative Commons Attribution (CC BY) license (https:// creativecommons.org/licenses/by/ $4.0 /)$.
1 Institute of Epidemiology, Helmholtz Zentrum München, German Research Center for Environmental Health, 85764 Neuherberg, Germany; lisa.maier@helmholtz-muenchen.de (L.M.); jule.filler@rocketmail.com (J.F.); thorand@helmholtz-muenchen.de (B.T.); peters@helmholtz-muenchen.de (A.P.)

2 Institute for Medical Information Processing, Biometry and Epidemiology (IBE), LMU Munich, 81377 Munich, Germany

3 Pettenkofer School of Public Health, LMU Munich, 81377 Munich, Germany

4 Department of Diagnostic and Interventional Radiology, Medical Center, University of Freiburg, 79106 Freiburg, Germany; ricarda.kruechten@uniklinik-freiburg.de (R.v.K.); johannanattenmueller@gmail.com (J.N.); fabian.bamberg@uniklinik-freiburg.de (F.B.); christopher.schlett@uniklinik-freiburg.de (C.L.S.)

5 Department of Radiology, University Hospital, LMU Munich, 80336 Munich, Germany; roberto.lorbeer@med.uni-muenchen.de

6 German Center for Cardiovascular Disease Research (DZHK), Partner Site Munich Heart Alliance, 80802 Munich, Germany; koenig@dhm.mhn.de

7 Department of Diagnostic and Interventional Radiology, University Hospital Heidelberg, 69120 Heidelberg, Germany

8 German Center for Diabetes Research (DZD), 85764 Neuherberg, Germany; rathmann@ddz.de

9 German Heart Center Munich, Technical University Munich, 80636 Munich, Germany

10 Institute of Epidemiology and Medical Biometry, University of Ulm, 89081 Ulm, Germany

11 Institute of Biometrics and Epidemiology, German Diabetes Center, 40225 Duesseldorf, Germany

* Correspondence: susanne.rospleszcz@helmholtz-muenchen.de; Tel.: +49-89-3187-4234

\begin{abstract}
Hepatic iron overload can cause severe organ damage; therefore, an early diagnosis and the identification of potential risk factors is crucial. We aimed to investigate the sex-specific distribution of hepatic iron content (HIC) in a population-based cohort and identify relevant associated factors from a panel of markers. We analyzed $\mathrm{N}=353$ participants from a cross-sectional sample (KORA FF4) who underwent whole-body magnetic resonance imaging. HIC was assessed by single-voxel spectroscopy with a high-speed T2-corrected multi-echo technique. A large panel of markers, including anthropometric, genetic, and laboratory values, as well as behavioral risk factors were assessed. Relevant factors associated with HIC were identified by variable selection based on LASSO regression with bootstrap resampling. HIC in the study sample (mean age at examination: 56.0 years, $58.4 \%$ men) was significantly lower in women (mean \pm SD: $39.2 \pm 4.1 \mathrm{~s}^{-1}$ ) than in men $\left(41.8 \pm 4.7 \mathrm{~s}^{-1}, p<0.001\right)$. Relevant factors associated with HIC were HbA1c as well as prediabetes for men and visceral adipose tissue as well as age for women. Hepatic fat, alcohol consumption, and genetic risk score for iron levels were associated with HIC in both sexes. In conclusion, there are sex-specific associations of HIC with markers of body composition, glucose metabolism, and alcohol consumption.
\end{abstract}

Keywords: hepatic iron; hepatic fat; magnetic resonance imaging; diabetes; markers

\section{Introduction}

Iron is an essential element in human organisms. It is of great importance for the transport and storage of oxygen; it also regulates cell survival and DNA synthesis. 
Consequently, deviations from normal ranges of stored body iron are associated with the development of certain pathologies. An excess in body iron storage leads to potential cell damage due to the generation of reactive oxygen species (ROS). These highly reactive oxygens induce lipid peroxidation and DNA damage, resulting, among others, in liver injuries [1].

In particular, the liver plays an important role in maintaining iron homeostasis. Hepcidin, a protein encoded by the HAMP gene and expressed within the liver, is the main regulator of iron homeostasis. Its expression is stimulated in the presence of iron overload to inhibit the absorption of iron in the intestine [2]. Moreover, the liver is the main storage site of iron and is susceptible to iron overload due to iron accumulation in hepatocytes [3]. Hepatic iron content (HIC) serves as a surrogate for whole-body iron storage [4]. Excessive hepatic iron storage can progress to severe liver diseases such as fibrosis, cirrhosis, or hepatocellular carcinoma [5].

Mechanisms responsible for the disruption of iron homeostasis and pathways associated with comorbidities are still insufficiently explored. However, studies have linked increased HIC with type 2 diabetes mellitus (T2DM) and insulin resistance [6], hypertension [7], and non-alcoholic fatty liver disease (NAFLD) [3], suggesting cross-talk between metabolic syndrome (MetS) and iron metabolism.

The increase in HIC to pathological levels occurs gradually [8]. Therefore, an early diagnosis of elevated HIC and the identification of relevant, potentially modifiable risk factors would be beneficial to prevent manifestations of iron-driven organ damage and further complications.

However, clinical assessment of HIC is challenging. Early presentations of hepatic iron overload range from asymptomatic to mild cases or patients presenting with predominantly non-specific symptoms [9]. Population-based studies are scarce since liver biopsy, the gold standard for HIC assessment, is an invasive procedure and not feasible at a population level. Hence, the majority of studies on HIC are based on small patient cohorts [10,11]. Alternatively, serum ferritin is regularly assessed as an indirect marker for body iron stores. Several population-based studies have already analyzed associations of serum ferritin with metabolic disorders [12,13]; however, the interpretability of this biomarker is limited as serum ferritin is also influenced by inflammation and coexisting liver diseases, and therefore might be artificially elevated [14].

Magnetic resonance imaging (MRI) has been recognized as a powerful non-invasive diagnostic tool to accurately assess HIC for a long time, particularly in patient collectives $[15,16]$. Nonetheless, only a few studies so far have investigated the distribution of HIC in population-based samples and reported early evidence on a limited number of associated factors $[17,18]$.

Therefore, we aim to determine the sex-specific distribution of MRI-derived HIC in a population-based study and identify relevant associated factors from a broad panel of markers on a population-based level.

\section{Results}

\subsection{Study Sample}

Characteristics of the study sample are provided in Table 1 . The average age of the participants at the time of examination was $56.0 \pm 9.1$ (mean \pm SD) years; $58.4 \%$ were male. Among the 353 participants, $12.2 \%$ had diagnosed diabetes, $23.5 \%$ had prediabetes, and $64.3 \%$ were normoglycemic. Men had significantly higher values of hepatic fat fraction (HFF) than women (median (IQR): 7.02\% (10.08) and 3.53\% (4.28), $p<0.001$, respectively).

Mean laboratory values were within the non-pathological range (for reference ranges, see Table S3). For example, liver enzymes were within normal ranges for both men and women (GGT: men 35.3 U/L, women: 19.6 U/L; AST: men 24.5 U/L, women: 20.0 U/L; and ALT: men $31.0 \mathrm{U} / \mathrm{L}$, women $21.0 \mathrm{U} / \mathrm{L}$ ). 
Table 1. Descriptive characteristics of the study participants by sex.

\begin{tabular}{|c|c|c|c|c|}
\hline & $\begin{array}{c}\text { Men } \\
(\mathrm{N}=206)\end{array}$ & $\begin{array}{c}\text { Women } \\
(\mathrm{N}=147)\end{array}$ & $\begin{array}{c}\text { Total } \\
(\mathrm{N}=353)\end{array}$ & $p$-Value ${ }^{\text {a }}$ \\
\hline Age (years) & $56.0 \pm 9.3$ & $56.1 \pm 9.0$ & $56.0 \pm 9.1$ & 0.928 \\
\hline \multicolumn{5}{|l|}{ Body Composition } \\
\hline Body weight (kg) & $89.2 \pm 13.4$ & $72.4 \pm 14.1$ & $82.2 \pm 16.0$ & $<0.001$ \\
\hline Height $(\mathrm{cm})$ & $178.01 \pm 6.66$ & $163.68 \pm 6.58$ & $172.04 \pm 9.68$ & $<0.001$ \\
\hline $\operatorname{BMI}\left(\mathrm{kg} / \mathrm{m}^{2}\right)$ & $28.2 \pm 4.1$ & $27.1 \pm 5.2$ & $27.7 \pm 4.7$ & 0.026 \\
\hline Waist circumference $(\mathrm{cm})$ & $102.7 \pm 11.6$ & $90.5 \pm 13.4$ & $97.6 \pm 13.7$ & $<0.001$ \\
\hline Hip circumference $(\mathrm{cm})$ & $106.5 \pm 7.1$ & $105.9 \pm 10.0$ & $106.3 \pm 8.5$ & 0.483 \\
\hline Subcutaneous fat (L) & $7.36 \pm 3.23$ & $8.72 \pm 3.90$ & $7.93 \pm 3.58$ & $<0.001$ \\
\hline Visceral fat (L) & $5.56 \pm 2.56$ & $2.79 \pm 1.97$ & $4.41 \pm 2.70$ & $<0.001$ \\
\hline Total fat (L) & $12.92 \pm 5.26$ & $11.51 \pm 5.43$ & $12.34 \pm 5.37$ & 0.015 \\
\hline \multicolumn{5}{|l|}{ Blood Lipids } \\
\hline Total cholesterol (mg/dL) & $217.5 \pm 38.1$ & $218.9 \pm 34.7$ & $218.1 \pm 36.7$ & 0.728 \\
\hline HDL-C (mg/dL) & $55.7 \pm 14.8$ & $71.1 \pm 17.7$ & $62.1 \pm 17.7$ & $<0.001$ \\
\hline LDL-C (mg/dL) & $142.2 \pm 33.9$ & $136.3 \pm 32.2$ & $139.7 \pm 33.3$ & 0.103 \\
\hline $\mathrm{TG}(\mathrm{mg} / \mathrm{dL})$ & $123.0(100.5)$ & $89.4(51.0)$ & $105.0(76.9)$ & $<0.001$ \\
\hline \multicolumn{5}{|l|}{ Markers of Glucose Metabolism } \\
\hline Fasting glucose (mg/dL) & $106.9 \pm 23.5$ & $98.1 \pm 16.5$ & $103.2 \pm 21.3$ & $<0.001$ \\
\hline Fasting insulin (mU/mL) & $11.8(7.8)$ & $9.3(5.4)$ & $8.8(7.4)$ & $<0.001$ \\
\hline HbA1c (\%) & $5.56 \pm 0.83$ & $5.51 \pm 0.49$ & $5.54 \pm 0.71$ & 0.540 \\
\hline $2 \mathrm{~h}$ insulin $(\mu \mathrm{U} / \mathrm{mL})$ & $46.0(70.5)^{b}$ & $42.0(39.5)^{c}$ & $44.0(51.8)^{d}$ & 0.412 \\
\hline $2 \mathrm{~h}$ glucose $(\mathrm{mg} / \mathrm{dL})$ & $117.4 \pm 44.5^{b}$ & $104.0 \pm 32.9^{c}$ & $111.6 \pm 40.4^{\mathrm{d}}$ & 0.003 \\
\hline Diabetes status & & & & 0.002 \\
\hline Diabetes & $16.0 \%(33)$ & $6.8 \%(10)$ & $12.2 \%(43)$ & \\
\hline Prediabetes & $26.7 \%(55)$ & $19.0 \%(28)$ & $23.5 \%(83)$ & \\
\hline Normoglycemic & $57.3 \%(118)$ & $74.1 \%(109)$ & $64.3 \%(227)$ & \\
\hline \multicolumn{5}{|l|}{ Markers of Renal Function } \\
\hline $\begin{array}{l}\text { Glomerular filtration rate } \\
\left(\mathrm{mL} / \mathrm{min} / 1.73 \mathrm{~m}^{2}\right)\end{array}$ & $93.6 \pm 16.7$ & $91.2 \pm 16.9$ & $92.6 \pm 16.8$ & 0.195 \\
\hline Uric acid $(\mathrm{mg} / \mathrm{dL})$ & $6.33 \pm 1.32$ & $4.57 \pm 1.11$ & $5.60 \pm 1.51$ & $<0.001$ \\
\hline Creatinine $(\mathrm{mg}(\mathrm{dL})$ & $0.96 \pm 0.13$ & $0.77 \pm 0.12$ & $0.88 \pm 0.16$ & 0.001 \\
\hline Albumin (g/dL) & $4.41 \pm 0.29$ & $4.28 \pm 0.27$ & $4.35 \pm 0.29$ & $<0.001$ \\
\hline Cystatin C (mg/L) & $0.89 \pm 0.14$ & $0.85 \pm 0.17$ & $0.88 \pm 0.16$ & 0.029 \\
\hline Urine albumin (mg/L) & $6.48(10.52)$ & $6.22(8.47)$ & $6.32(8.85)$ & 0.431 \\
\hline Urine creatinine $(\mathrm{g} / \mathrm{L})$ & $1.75 \pm 0.74$ & $1.39 \pm 0.82$ & $1.60 \pm 0.79$ & $<0.001$ \\
\hline \multicolumn{5}{|l|}{ Complete Blood Count } \\
\hline Hematocrit (L/L) & $0.43 \pm 0.03$ & $0.39 \pm 0.03$ & $0.42 \pm 0.03$ & $<0.001$ \\
\hline Thrombocytes (/nL) & $221.1 \pm 51.6$ & $244.5 \pm 52.2$ & $230.9 \pm 53.1$ & $<0.001$ \\
\hline Erythrocytes (/pL) & $4.87 \pm 0.37$ & $4.45 \pm 0.37$ & $4.70 \pm 0.40$ & $<0.001$ \\
\hline Leucocytes $(/ \mathrm{nL})$ & $5.61(1.93)$ & $5.66(1.98)$ & $5.65(1.91)$ & 0.576 \\
\hline Hemoglobin (g/L) & $150.4 \pm 10.1$ & $134.8 \pm 9.8$ & $143.9 \pm 12.6$ & $<0.001$ \\
\hline \multicolumn{5}{|l|}{ Electrolyte Panel } \\
\hline Potassium (mmol/L) & $4.32 \pm 0.31$ & $4.22 \pm 0.22$ & $4.28 \pm 0.28$ & 0.001 \\
\hline Sodium (mmol/L) & $139.0(4.0)$ & $139.0(3.5)$ & $139.0(4.0)$ & 0.448 \\
\hline Magnesium (mmol/L) & $0.85 \pm 0.08$ & $0.87 \pm 0.08$ & $0.86 \pm 0.07$ & 0.062 \\
\hline Phosphate (mmol/L) & $0.98 \pm 0.13$ & $1.12 \pm 0.14$ & $1.04 \pm 0.15$ & $<0.001$ \\
\hline
\end{tabular}


Table 1. Cont.

\begin{tabular}{|c|c|c|c|c|}
\hline & $\begin{array}{c}\text { Men } \\
(\mathrm{N}=206)\end{array}$ & $\begin{array}{c}\text { Women } \\
(\mathrm{N}=147)\end{array}$ & $\begin{array}{c}\text { Total } \\
(\mathrm{N}=353)\end{array}$ & $p$-Value ${ }^{\mathrm{a}}$ \\
\hline \multicolumn{5}{|l|}{ Blood Pressure Parameters } \\
\hline SBP (mmHg) & $125.5 \pm 16.0$ & $113.0 \pm 14.9$ & $120.3 \pm 16.4$ & $<0.001$ \\
\hline $\mathrm{DBP}(\mathrm{mmHg})$ & $77.6 \pm 10.3$ & $71.8 \pm 8.2$ & $75.3 \pm 9.9$ & $<0.001$ \\
\hline Hypertension & $37.4 \%(77)$ & $25.9 \%(38)$ & $32.6 \%(115)$ & 0.025 \\
\hline \multicolumn{5}{|l|}{ Liver Parameters } \\
\hline GGT (U/L) & $35.3(33.9)$ & $19.6(17.5)$ & $27.0(28.0)$ & $<0.001$ \\
\hline AST (U/L) & $24.5(9.0)$ & $20.0(8.0)$ & $23.0(9.0)$ & $<0.001$ \\
\hline ALT (U/L) & $31.0(15.8)$ & $21.00(12.0)$ & $27.0(17.0)$ & $<0.001$ \\
\hline Hepatic iron $\left(\mathrm{s}^{-1}\right)$ & $41.8 \pm 4.7$ & $39.2 \pm 4.1$ & $40.7 \pm 4.6$ & $<0.001$ \\
\hline Right liver lobe $\left(\mathrm{s}^{-1}\right)$ & $42.4 \pm 5.4$ & $39.7 \pm 4.3$ & $41.3 \pm 5.2$ & $<0.001$ \\
\hline Left liver lobe $\left(\mathrm{s}^{-1}\right)$ & $41.1 \pm 5.4$ & $38.7 \pm 4.7$ & $40.1 \pm 5.2$ & $<0.001$ \\
\hline Hepatic fat fraction $(\%)$ & $7.02(10.08)$ & $3.53(4.28)$ & $5.38(7.92)$ & $<0.001$ \\
\hline Right liver lobe (\%) & $7.78(9.99)$ & $3.96(4.72)$ & $6.10(8.99)$ & $<0.001$ \\
\hline Left liver lobe (\%) & $6.39(10.62)$ & $3.16(4.34)$ & $4.53(7.63)$ & $<0.001$ \\
\hline \multicolumn{5}{|l|}{ Further Laboratory Values } \\
\hline Alkaline phosphatase (U/L) & $65.9 \pm 17.9$ & $67.6 \pm 23.6$ & $66.6 \pm 20.5$ & 0.448 \\
\hline $\mathrm{CRP}(\mathrm{mg} / \mathrm{L})$ & $1.09(1.70)$ & $1.26(2.00)$ & $1.12(1.78)$ & 0.349 \\
\hline Vitamin D (ng/mL) & $24.3 \pm 11.8$ & $22.2 \pm 11.3$ & $23.4 \pm 11.6$ & 0.094 \\
\hline Troponin T (pg/mL) & $3.55(5.20)$ & $1.50(0.77)$ & $1.50(3.82)$ & $<0.001$ \\
\hline \multicolumn{5}{|l|}{ Behavioral Risk Factors } \\
\hline Alcohol consumption (g/day) & $20.1(36.5)$ & $3.1(12.8)$ & $8.6(25.9)$ & $<0.001$ \\
\hline Smoking status & & & & 0.243 \\
\hline Smoker & $19.9 \%(41)$ & $22.4 \%(33)$ & $21.0 \%(74)$ & \\
\hline Ex-smoker & $46.1 \%(95)$ & $35.4 \%(52)$ & $41.6 \%(147)$ & \\
\hline Never-smoker & $34.0 \%(70)$ & $42.2 \%(62)$ & $37.4 \%(132)$ & \\
\hline Pack years & $17.8(28.7)^{\mathrm{e}}$ & $10.9(17.0)^{f}$ & $15.2(23.2)^{g}$ & $<0.001$ \\
\hline Physical activity & & & & 0.046 \\
\hline Active & $55.3 \%(114)$ & $66.0 \%(97)$ & $59.8 \%(211)$ & \\
\hline Inactive & $44 . \%(92)$ & $34.0 \%(50)$ & $40.2 \%(142)$ & \\
\hline \multicolumn{5}{|l|}{ Medication Intake } \\
\hline Beta blockers & $11.7 \%(24)$ & $11.6 \%(17)$ & $11.6 \%(41)$ & 1.000 \\
\hline ACE inhibitors & $8.7 \%(18)$ & $13.6 \%(20)$ & $10.8 \%(38)$ & 0.169 \\
\hline Calcium antagonists & $6.8 \%(14)$ & $7.5 \%(11)$ & $7.1 \%(25)$ & 0.822 \\
\hline Diuretics & $11.7 \%(24)$ & $13.6 \%(20)$ & $12.5 \%(44)$ & 0.620 \\
\hline Antihypertensives & $23.3 \%(48)$ & $25.2 \%(37)$ & $24.1 \%(85)$ & 0.709 \\
\hline Lipid-lowering agents & $10.2 \%(21)$ & $10.2 \%(15)$ & $10.2 \%(36)$ & 1.000 \\
\hline Treatment of hyperuricemia & $4.4 \%(9)$ & $0 \%(0)$ & $2.5 \%(9)$ & 0.012 \\
\hline
\end{tabular}

a $p$-values are from t-tests, Mann-Whitney $\mathrm{U}$ tests, and $\mathrm{X}^{2}$ tests, respectively. Abbreviations: SBP, systolic blood pressure; DBP, diastolic blood pressure; HDL-C, high-density lipoprotein cholesterol; LDL-C, low-density lipoprotein cholesterol; TG, triglycerides; GGT, gammaglutamyl transferase; AST, aspartate aminotransferase; ALT, alanine aminotransferase; CRP, c-reactive protein; HFF, hepatic fat fraction. ${ }^{\mathrm{b}}$ Male participants with missing $2 \mathrm{~h}$ insulin/glucose data from OGTT excluded, $\mathrm{N}=184 .{ }^{\mathrm{c}}$ Female participants with missing $2 \mathrm{~h}$ insulin/glucose data from OGTT excluded, $\mathrm{N}=139 .{ }^{\mathrm{d}}$ Participants with missing $2 \mathrm{~h}$ insulin/glucose data from OGTT excluded, $\mathrm{N}=323$. ${ }^{\mathrm{e}}$ Missing values and never-smokers excluded, $\mathrm{N}=130 .{ }^{\mathrm{f}}$ Missing values and never-smokers excluded, $\mathrm{N}=83 .{ }^{\mathrm{g}}$ Missing values and never-smokers excluded, $\mathrm{N}=213$. 


\subsection{Distribution of HIC and Correlation with Age, HFF, and Genetic Risk Score}

HIC was significantly higher in men than in women $\left(41.8 \mathrm{~s}^{-1} \pm 4.7\right.$ and $39.2 \mathrm{~s}^{-1} \pm 4.1$, $p<0.001$, respectively). Applying a cutoff value of $\mathrm{R} 2^{*}>41 \mathrm{~s}^{-1}$, as defined within the SHIP study [17], $44.5 \%$ of the participants had mild hepatic iron overload. However, no participant had moderate-to-severe iron overload (cutoffs of $62.5 \mathrm{~s}^{-1}$ and $70.1 \mathrm{~s}^{-1}$, respectively). Age was significantly correlated with HIC in women (rho $=0.48, p<0.001$ ) but not in men (rho $=0.11, p=0.13$, see Figure 1). HFF was correlated with HIC in both men and women (rho $=0.32, p<0.001$ and rho $=0.51, p<0.001$, respectively, see Figure 1 ).

(a)

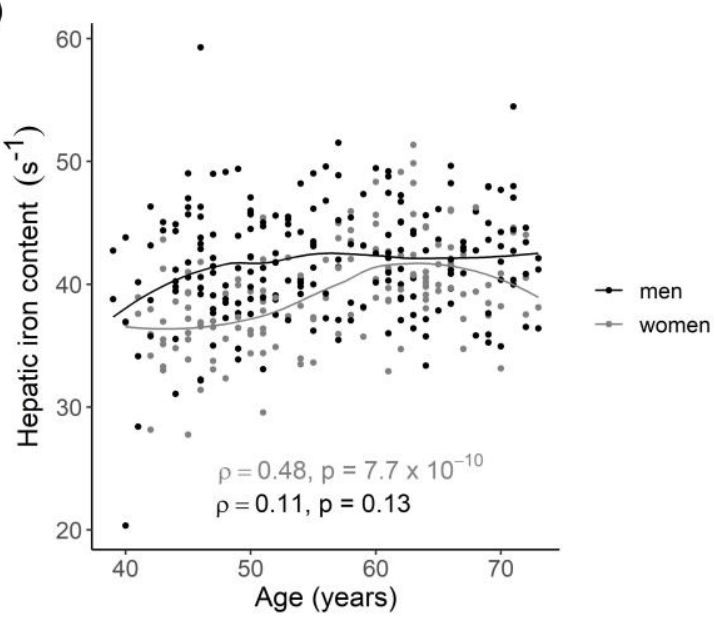

(b)

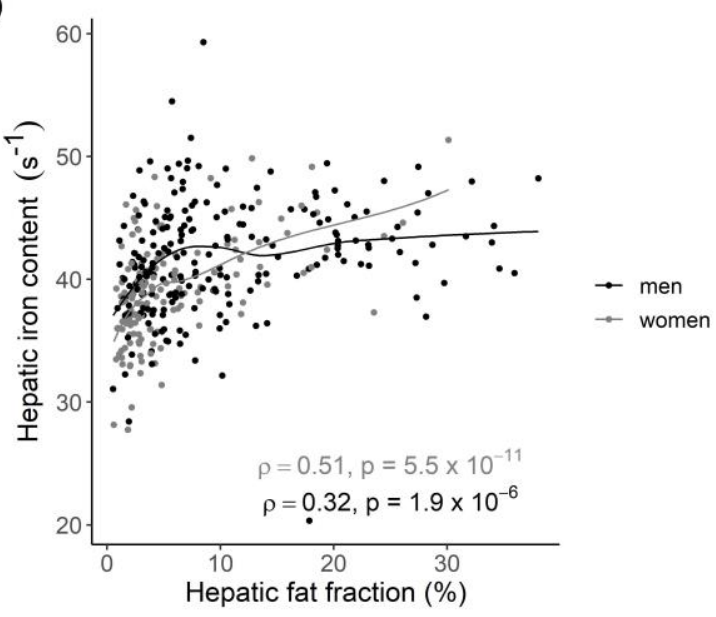

Figure 1. Scatter plots showing the sex-specific correlations of HIC with (a) age and (b) HFF, respectively. Lines denote the regression lines derived from locally weighted smoothing. Rho denotes the Spearman's rank correlation coefficients.

Using a cutoff of HFF $\geq 5.6 \%, 129$ men (62.6\%) and 44 women $(29.9 \%)$ had hepatic steatosis. HIC was higher in individuals with hepatic steatosis compared to those without (men: $42.8 \mathrm{~s}^{-1}$ vs. $40.0 \mathrm{~s}^{-1}, p<0.001$; women: $41.7 \mathrm{~s}^{-1}$ vs. $38.1 \mathrm{~s}^{-1}, p<0.001$ ) (Figure S1).

HIC increased with quartiles of the genetic risk score (Figure 2), resulting in significant differences in HIC between the lowest and highest quartile (men: $40.6 \mathrm{~s}^{-1}$ vs. $43.1 \mathrm{~s}^{-1}$, $p=0.007$; women: $37.7 \mathrm{~s}^{-1}$ vs. $40.2 \mathrm{~s}^{-1}, p=0.03$ ). 
(a)

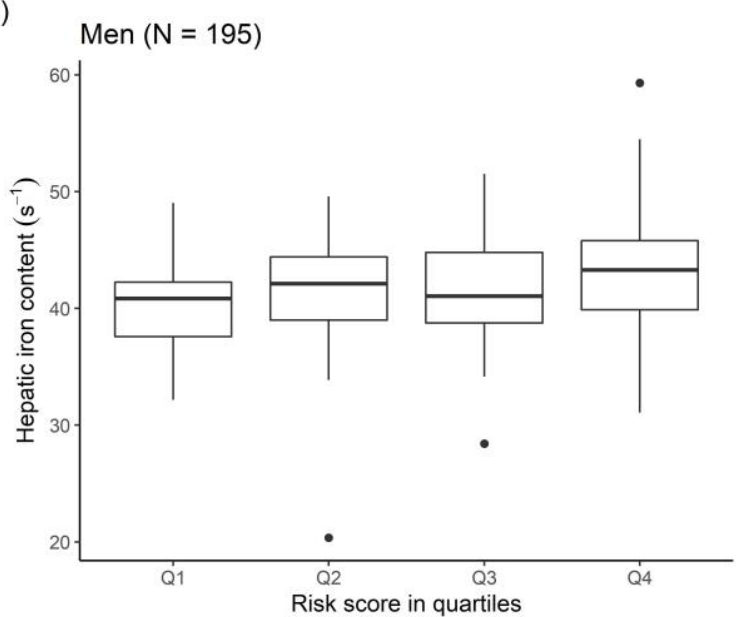

(b)

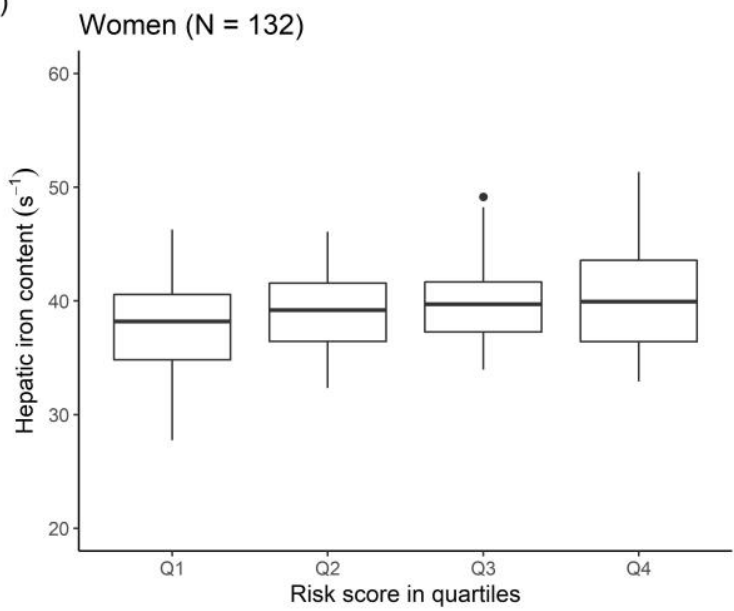

Figure 2. Boxplots of HIC according to genetic risk score quartiles for (a) men and (b) women.

\subsection{Identification of Relevant Associated Variables}

Relevant factors associated with HIC, identified by least absolute shrinkage and selection operator (LASSO) regression, are depicted in Figure 3. For men the most frequently selected variables were $\mathrm{HFF}, \mathrm{HbA} 1 \mathrm{c}$, and prediabetes, whereas for women the most frequently selected variables were age, HFF, and visceral adipose tissue (VAT). Alcohol consumption was selected in both men and women. When excluding HFF from the analysis, results were mainly stable. Further selected parameters included fasting insulin, uric acid, triglycerides, vitamin D, and beta blocker use (Figure S2).

In a sensitivity analysis including only participants who underwent an OGTT $(\mathrm{N}=323)$, results remained largely stable; $2 \mathrm{~h}$ glucose and $2 \mathrm{~h}$ insulin were additionally selected as relevant covariates (Figures S3 and S4).

The selected variables also remained mostly the same in the genetic analyses (Figure 4). Leucocytes were further selected for both sexes and the genetic risk score was among the most frequently selected variables. 
(a)

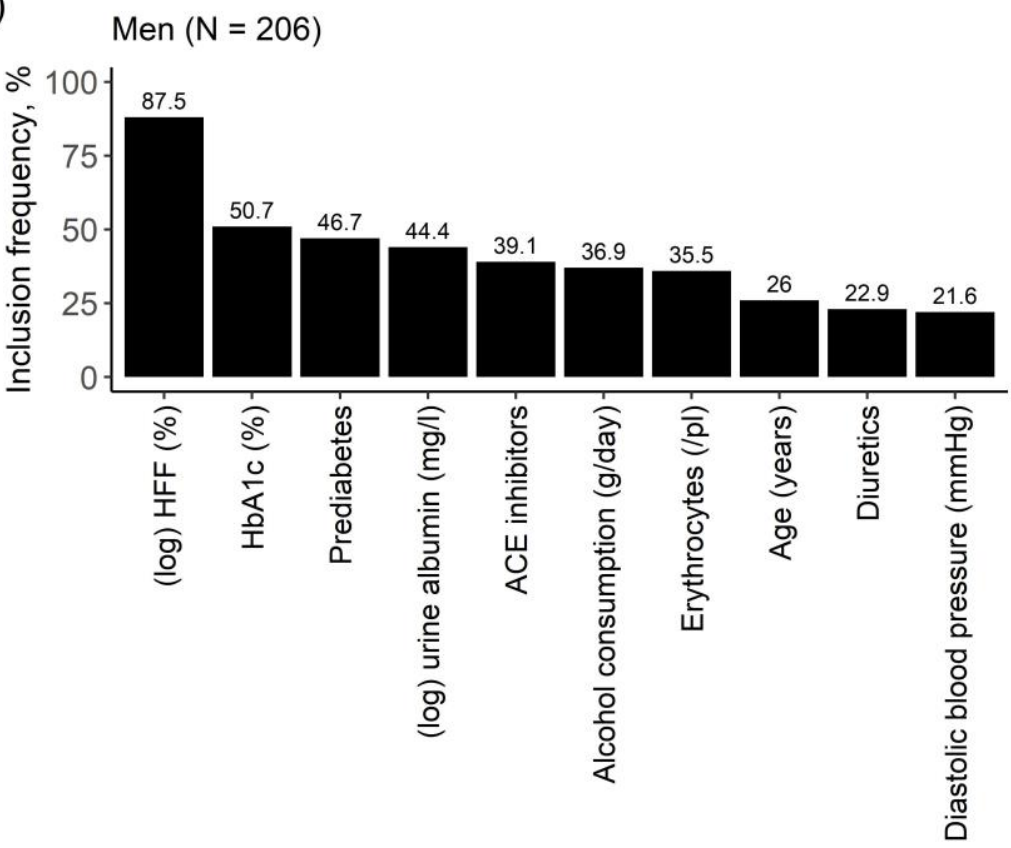

(b)

Women $(\mathrm{N}=147)$

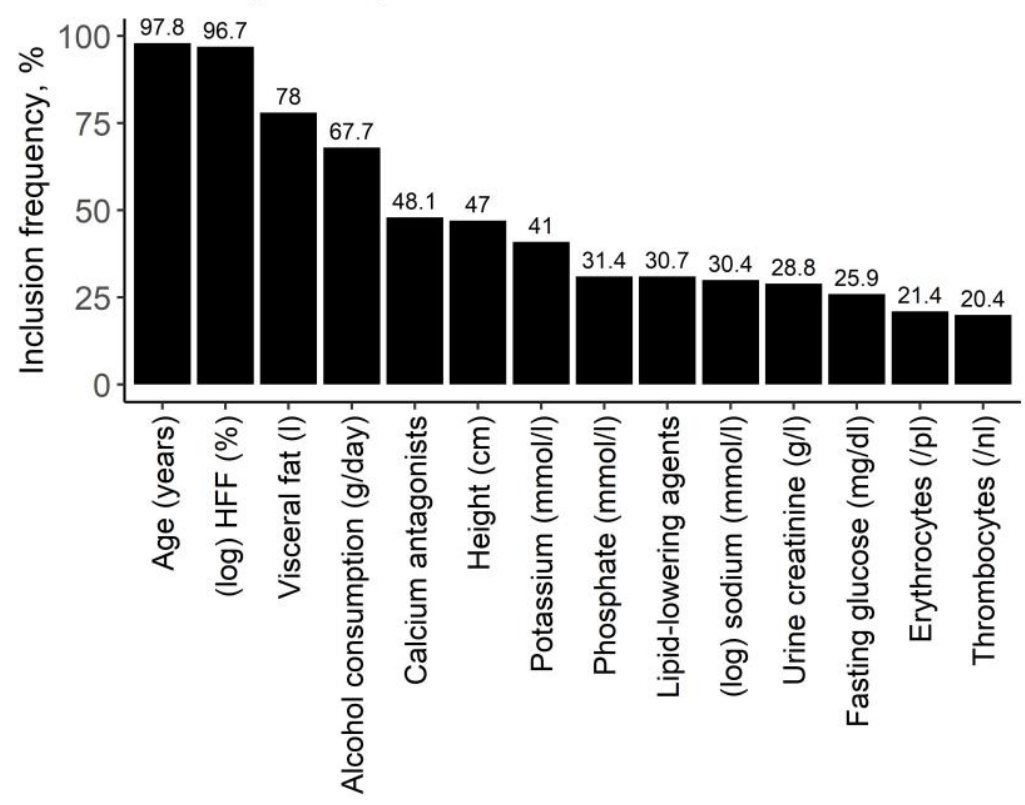

Figure 3. Bar diagrams of results from the model including HFF for (a) men and (b) women. Relevant variables were identified by variable selection through LASSO regression on 1000 bootstrap samples. On the y-axis: inclusion frequency of the respective variable across 1000 bootstrap samples. Only variables with an inclusion frequency $>20 \%$ are presented. 
(a)

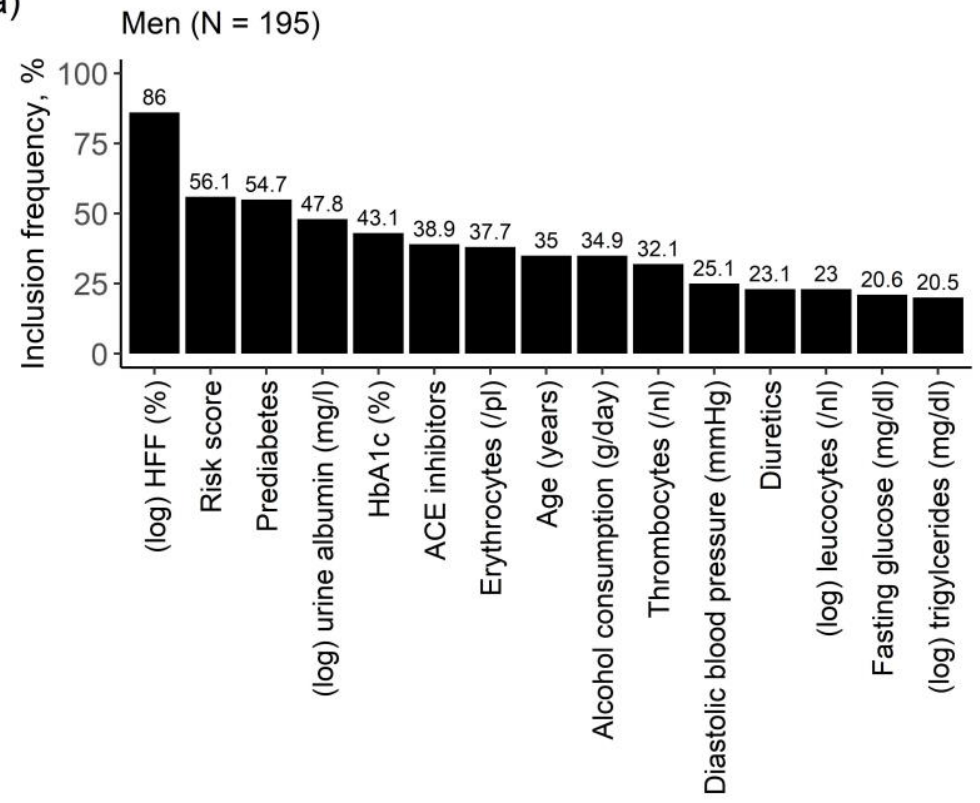

(b)

Women $(\mathrm{N}=132)$

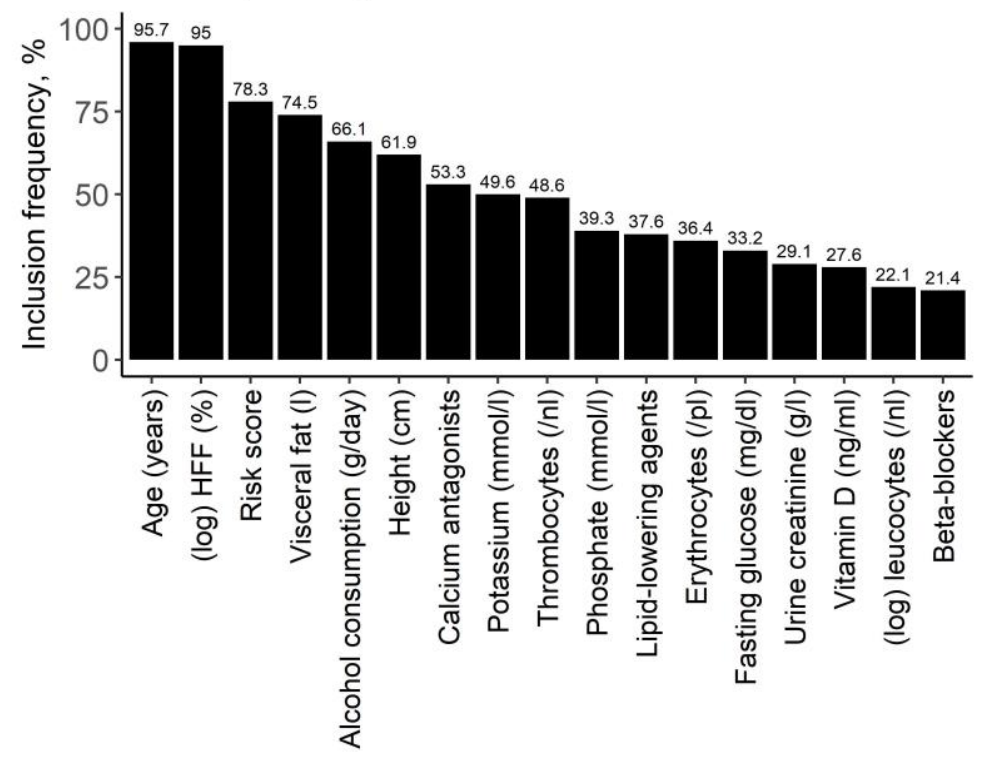

Figure 4. Bar diagrams of results from the model including genetic risk score for (a) men and (b) women. Relevant variables were identified by variable selection through LASSO regression on 1000 bootstrap samples. On the y-axis: inclusion frequency of the respective variable across 1000 bootstrap samples. Only variables with an inclusion frequency $>20 \%$ are presented.

\subsection{Strength of Effects}

Tables 2 and 3 show the results of unpenalized linear regression analyses with and without adjustment for HFF for all variables that were identified in LASSO regression.

In general, associations attenuated after adjustment for HFF. The explained variance in outcome (adjusted $\mathrm{R}^{2}$ ) was generally higher in women (21-39\%) than in men (2-14\%).

In men, of all variables identified by LASSO regression, $\mathrm{HFF}, \mathrm{HbA1c}$, urine albumin, alcohol consumption, ACE inhibitors, and diuretics were also significantly associated with $\mathrm{HIC}$ in unpenalized regression. Higher values of $\mathrm{HbA1c}$ were negatively associated with HIC $(\beta=-1.44, p<0.001)$, whereas higher consumption of alcohol was associated with increased HIC $(\beta=0.02, p=0.04)$. Urine albumin and diuretics showed a negative relationship with HIC ( $\beta=-0.80, p<0.01$ and $\beta=-2.50, p=0.01$, respectively). 
In women, age, HFF, potassium, alcohol consumption, and calcium antagonists were also significantly associated with HIC in unpenalized regression. We revealed a negative relationship between HIC and potassium and calcium antagonist intake, respectively ( $\beta=-2.74, p=0.03$ and $\beta=-2.24, p=0.03)$. Alcohol consumption was also associated with increased HIC $(\beta=0.05, p<0.01)$.

The continuous genetic risk score was positively associated with HIC in both men and women ( $\beta=0.64, p<0.01$ and $\beta=0.65, p<0.01$, respectively).

Table 2. Men: Results from unpenalized linear regression analyses. $\beta$ denotes the regression coefficient of the respective variable for outcome HIC. Adjusted $\mathrm{R}^{2}$ denotes the explained variance in HIC. Only variables with an inclusion frequency $>20 \%$ in the variable selection procedure are presented.

\begin{tabular}{|c|c|c|c|c|c|}
\hline & Adjustment & $\beta$ & $95 \% \mathrm{CI}$ & $p$-Value & Adjusted $\mathbf{R}^{2}$ \\
\hline \multicolumn{6}{|l|}{ Blood Lipids } \\
\hline$(\mathrm{log})$ trigylcerides $(\mathrm{mg} / \mathrm{dL})$ & $\begin{array}{c}\text { Age + HFF } \\
\text { Age }\end{array}$ & $\begin{array}{l}0.25 \\
1.11\end{array}$ & $\begin{array}{l}-0.94 ; 1.44 \\
-0.01 ; 2.22\end{array}$ & $\begin{array}{l}0.68 \\
0.05\end{array}$ & $\begin{array}{l}0.08 \\
0.03\end{array}$ \\
\hline \multicolumn{6}{|l|}{ Markers of Glucose Metabolism } \\
\hline (log) fasting insulin (mU/mL) & $\begin{array}{c}\text { Age + HFF } \\
\text { Age }\end{array}$ & $\begin{array}{c}-0.42 \\
0.97\end{array}$ & $\begin{array}{l}-1.73 ; 0.9 \\
-0.14 ; 2.07\end{array}$ & $\begin{array}{l}0.53 \\
0.09 \\
\end{array}$ & $\begin{array}{l}0.08 \\
0.02\end{array}$ \\
\hline $\mathrm{HbA1c}(\%)$ & $\begin{array}{l}\text { Age + HFF } \\
\text { Age }\end{array}$ & $\begin{array}{l}-1.44 \\
-1.11\end{array}$ & $\begin{array}{l}-2.17 ;-0.71 \\
-1.87 ;-0.36\end{array}$ & $\begin{array}{l}0.00 \\
0.00\end{array}$ & $\begin{array}{l}0.14 \\
0.05\end{array}$ \\
\hline Prediabetes & $\begin{array}{c}\text { Age + HFF } \\
\text { Age }\end{array}$ & $\begin{array}{l}0.92 \\
2.13\end{array}$ & $\begin{array}{l}-0.67 ; 2.5 \\
0.64 ; 3.63\end{array}$ & $\begin{array}{l}0.25 \\
0.01\end{array}$ & $\begin{array}{l}0.11 \\
0.05\end{array}$ \\
\hline \multicolumn{6}{|l|}{ Markers of Renal Function } \\
\hline Uric acid (mg/dL) & $\begin{array}{l}\text { Age }+ \text { HFF } \\
\text { Age }\end{array}$ & $\begin{array}{l}0.23 \\
0.49\end{array}$ & $\begin{array}{c}-0.27 ; 0.72 \\
0.01 ; 0.97\end{array}$ & $\begin{array}{l}0.37 \\
0.05\end{array}$ & $\begin{array}{l}0.08 \\
0.03\end{array}$ \\
\hline$(\log )$ urine albumin $(\mathrm{mg} / \mathrm{L})$ & $\begin{array}{c}\text { Age + HFF } \\
\text { Age }\end{array}$ & $\begin{array}{l}-0.80 \\
-0.69\end{array}$ & $\begin{array}{c}-1.29 ;-0.31 \\
-1.2 ;-0.19\end{array}$ & $\begin{array}{l}0.00 \\
0.01\end{array}$ & $\begin{array}{l}0.12 \\
0.04\end{array}$ \\
\hline \multicolumn{6}{|l|}{ Complete Blood Count } \\
\hline Thrombocytes $(/ \mathrm{nL})$ & $\begin{array}{l}\text { Age }+ \text { HFF } \\
\text { Age }\end{array}$ & $\begin{array}{l}-0.01 \\
-0.01\end{array}$ & $\begin{array}{c}-0.02 ; 0.01 \\
-0.02 ; 0\end{array}$ & $\begin{array}{l}0.38 \\
0.20\end{array}$ & $\begin{array}{l}0.08 \\
0.02\end{array}$ \\
\hline Erythrocytes (/pL) & $\begin{array}{c}\text { Age + HFF } \\
\text { Age }\end{array}$ & $\begin{array}{l}-1.35 \\
-1.03\end{array}$ & $\begin{array}{l}-3.05 ; 0.35 \\
-2.79 ; 0.73\end{array}$ & $\begin{array}{l}0.12 \\
0.25\end{array}$ & $\begin{array}{l}0.09 \\
0.02\end{array}$ \\
\hline \multicolumn{6}{|l|}{ Blood Pressure } \\
\hline Systolic blood pressure (mmHg) & $\begin{array}{c}\text { Age }+ \text { HFF } \\
\text { Age }\end{array}$ & $\begin{array}{l}0.01 \\
0.04 \\
\end{array}$ & $\begin{array}{c}-0.03 ; 0.06 \\
0 ; 0.08\end{array}$ & $\begin{array}{l}0.48 \\
0.05\end{array}$ & $\begin{array}{l}0.08 \\
0.03\end{array}$ \\
\hline Diastolic blood pressure (mmHg) & $\begin{array}{c}\text { Age + HFF } \\
\text { Age }\end{array}$ & $\begin{array}{l}0.04 \\
0.08\end{array}$ & $\begin{array}{c}-0.02 ; 0.11 \\
0.02 ; 0.14\end{array}$ & $\begin{array}{l}0.17 \\
0.01\end{array}$ & $\begin{array}{l}0.09 \\
0.04\end{array}$ \\
\hline \multicolumn{6}{|l|}{ Liver Parameters } \\
\hline$(\log )$ hepatic fat fraction $(\%)$ & Age & 1.46 & $0.74 ; 2.19$ & 0.00 & 0.08 \\
\hline \multicolumn{6}{|l|}{ Behavioral Risk Factors } \\
\hline Alcohol consumption (g/day) & $\begin{array}{c}\text { Age + HFF } \\
\text { Age }\end{array}$ & $\begin{array}{l}0.02 \\
0.03\end{array}$ & $\begin{array}{c}0 ; 0.05 \\
0.01 ; 0.05\end{array}$ & $\begin{array}{l}0.04 \\
0.01\end{array}$ & $\begin{array}{l}0.10 \\
0.04\end{array}$ \\
\hline \multicolumn{6}{|l|}{ Medication Intake } \\
\hline ACE inhibitors & $\begin{array}{c}\text { Age + HFF } \\
\text { Age }\end{array}$ & $\begin{array}{l}-3.61 \\
-2.78\end{array}$ & $\begin{array}{l}-5.79 ;-1.43 \\
-5.03 ;-0.53\end{array}$ & $\begin{array}{l}0.00 \\
0.02\end{array}$ & $\begin{array}{l}0.12 \\
0.04\end{array}$ \\
\hline Diuretics & $\begin{array}{c}\text { Age }+ \text { HFF } \\
\text { Age }\end{array}$ & $\begin{array}{l}-2.50 \\
-1.97\end{array}$ & $\begin{array}{c}-4.44 ;-0.56 \\
-3.97 ; 0.04\end{array}$ & $\begin{array}{l}0.01 \\
0.05\end{array}$ & $\begin{array}{l}0.11 \\
0.03\end{array}$ \\
\hline \multicolumn{6}{|l|}{ Genetic Analyses $(\mathrm{N}=195)$} \\
\hline Genetic risk score, continuous & Age + HFF & 0.64 & $0.16 ; 1.12$ & 0.01 & 0.12 \\
\hline
\end{tabular}

CI, confidence interval; HFF, hepatic fat fraction. 
Table 3. Women: Results from unpenalized linear regression analyses. $\beta$ denotes the regression coefficient of the respective variable for outcome HIC. Adjusted $\mathrm{R}^{2}$ denotes the explained variance in HIC. Presented are only variables with an inclusion frequency $>20 \%$ in the variable selection procedure.

\begin{tabular}{|c|c|c|c|c|c|}
\hline & Adjustment & $\beta$ & $95 \% \mathrm{CI}$ & $p$-Value & Adjusted $R^{2}$ \\
\hline \multicolumn{6}{|l|}{ Body Composition } \\
\hline Height (cm) & $\begin{array}{c}\text { Age }+ \text { HFF } \\
\text { Age }\end{array}$ & $\begin{array}{l}-0.04 \\
-0.05 \\
\end{array}$ & $\begin{array}{l}-0.13 ; 0.05 \\
-0.15 ; 0.05\end{array}$ & $\begin{array}{l}0.40 \\
0.29 \\
\end{array}$ & $\begin{array}{l}0.36 \\
0.21 \\
\end{array}$ \\
\hline Visceral fat (L) & $\begin{array}{c}\text { Age }+ \text { HFF } \\
\text { Age }\end{array}$ & $\begin{array}{l}0.01 \\
0.81 \\
\end{array}$ & $\begin{array}{c}-0.12 ; 0.14 \\
0.5 ; 1.13\end{array}$ & $\begin{array}{l}0.91 \\
0.00 \\
\end{array}$ & $\begin{array}{l}0.35 \\
0.33 \\
\end{array}$ \\
\hline \multicolumn{6}{|l|}{ Blood Lipid Markers } \\
\hline$(\log )$ trigylcerides $(\mathrm{mg} / \mathrm{dL})$ & $\begin{array}{c}\text { Age }+ \text { HFF } \\
\text { Age }\end{array}$ & $\begin{array}{l}-0.20 \\
1.70 \\
\end{array}$ & $\begin{array}{l}-1.8 ; 1.4 \\
0.14 ; 3.26 \\
\end{array}$ & $\begin{array}{l}0.81 \\
0.03\end{array}$ & $\begin{array}{l}0.35 \\
0.23 \\
\end{array}$ \\
\hline \multicolumn{6}{|l|}{ Markers of Glucose Metabolism } \\
\hline Fasting glucose $(\mathrm{mg} / \mathrm{dL})$ & $\begin{array}{c}\text { Age }+ \text { HFF } \\
\text { Age }\end{array}$ & $\begin{array}{l}0.01 \\
0.05 \\
\end{array}$ & $\begin{array}{c}-0.02 ; 0.05 \\
0.01 ; 0.09\end{array}$ & $\begin{array}{l}0.47 \\
0.01 \\
\end{array}$ & $\begin{array}{l}0.36 \\
0.24 \\
\end{array}$ \\
\hline \multicolumn{6}{|l|}{ Markers of Renal Function } \\
\hline Urine creatinine $(\mathrm{g} / \mathrm{L})$ & $\begin{array}{c}\text { Age + HFF } \\
\text { Age }\end{array}$ & $\begin{array}{l}-0.47 \\
-0.14\end{array}$ & $\begin{array}{l}-1.14 ; 0.21 \\
-0.89 ; 0.6\end{array}$ & $\begin{array}{l}0.17 \\
0.70\end{array}$ & $\begin{array}{l}0.36 \\
0.21\end{array}$ \\
\hline \multicolumn{6}{|l|}{ Complete Blood Count } \\
\hline $\begin{array}{l}\text { Thrombocytes }(/ \mathrm{nL}) \\
\text { Erythrocytes }(/ \mathrm{pL})\end{array}$ & $\begin{array}{c}\text { Age }+ \text { HFF } \\
\text { Age } \\
\text { Age }+ \text { HFF } \\
\text { Age }\end{array}$ & $\begin{array}{c}0.01 \\
0.00 \\
-1.24 \\
-0.91 \\
\end{array}$ & $\begin{array}{l}-0.01 ; 0.02 \\
-0.01 ; 0.01 \\
-3.02 ; 0.55 \\
-2.9 ; 1.07\end{array}$ & $\begin{array}{l}0.34 \\
0.71 \\
0.17 \\
0.36\end{array}$ & $\begin{array}{l}0.36 \\
0.21 \\
0.36 \\
0.21 \\
\end{array}$ \\
\hline \multicolumn{6}{|l|}{ Electrolyte Panel } \\
\hline Potassium (mmol/L) & $\begin{array}{c}\text { Age }+ \text { HFF } \\
\text { Age }\end{array}$ & $\begin{array}{l}-2.74 \\
-2.44 \\
\end{array}$ & $\begin{array}{c}-5.13 ;-0.34 \\
-5.11 ; 0.22\end{array}$ & $\begin{array}{l}0.03 \\
0.07 \\
\end{array}$ & $\begin{array}{l}0.38 \\
0.22 \\
\end{array}$ \\
\hline$(\log )$ sodium $(\mathrm{mmol} / \mathrm{L})$ & $\begin{array}{c}\text { Age }+ \text { HFF } \\
\text { Age }\end{array}$ & $\begin{array}{l}-19.63 \\
-40.47\end{array}$ & $\begin{array}{c}-45.67 ; 6.4 \\
-67.31 ;-13.63 \\
\end{array}$ & $\begin{array}{l}0.14 \\
0.00\end{array}$ & $\begin{array}{l}0.36 \\
0.25\end{array}$ \\
\hline Phosphate (mmol/L) & $\begin{array}{c}\text { Age }+ \text { HFF } \\
\text { Age }\end{array}$ & $\begin{array}{l}2.62 \\
0.61 \\
\end{array}$ & $\begin{array}{l}-1.51 ; 6.76 \\
-3.94 ; 5.15 \\
\end{array}$ & $\begin{array}{l}0.21 \\
0.79 \\
\end{array}$ & $\begin{array}{l}0.36 \\
0.21 \\
\end{array}$ \\
\hline \multicolumn{6}{|l|}{ Liver Parameters } \\
\hline$(\log )$ hepatic fat fraction $(\%)$ & Age & 2.08 & $1.38 ; 2.79$ & 0.00 & 0.36 \\
\hline \multicolumn{6}{|l|}{ Further Laboratory Values } \\
\hline Vitamin D (ng/mL) & $\begin{array}{c}\text { Age }+ \text { HFF } \\
\text { Age }\end{array}$ & $\begin{array}{l}-0.02 \\
-0.04\end{array}$ & $\begin{array}{l}-0.07 ; 0.03 \\
-0.1 ; 0.01\end{array}$ & $\begin{array}{l}0.46 \\
0.10\end{array}$ & $\begin{array}{l}0.36 \\
0.22 \\
\end{array}$ \\
\hline \multicolumn{6}{|l|}{ Behavioral Risk Factors } \\
\hline Alcohol consumption (g/day) & $\begin{array}{c}\text { Age }+ \text { HFF } \\
\text { Age }\end{array}$ & $\begin{array}{l}0.05 \\
0.07 \\
\end{array}$ & $\begin{array}{l}0.02 ; 0.09 \\
0.03 ; 0.11 \\
\end{array}$ & $\begin{array}{l}0.00 \\
0.00\end{array}$ & $\begin{array}{l}0.39 \\
0.26 \\
\end{array}$ \\
\hline \multicolumn{6}{|l|}{ Medication Intake } \\
\hline Beta blockers & $\begin{array}{c}\text { Age }+ \text { HFF } \\
\text { Age }\end{array}$ & $\begin{array}{l}0.31 \\
1.69 \\
\end{array}$ & $\begin{array}{l}-1.53 ; 2.15 \\
-0.26 ; 3.63 \\
\end{array}$ & $\begin{array}{l}0.74 \\
0.09 \\
\end{array}$ & $\begin{array}{l}0.35 \\
0.22 \\
\end{array}$ \\
\hline Calcium antagonists & $\begin{array}{c}\text { Age + HFF } \\
\text { Age }\end{array}$ & $\begin{array}{l}-2.24 \\
-2.35\end{array}$ & $\begin{array}{l}-4.29 ;-0.19 \\
-4.63 ;-0.07\end{array}$ & $\begin{array}{l}0.03 \\
0.04\end{array}$ & $\begin{array}{l}0.37 \\
0.23 \\
\end{array}$ \\
\hline Lipid-lowering agents & $\begin{array}{c}\text { Age }+ \text { HFF } \\
\text { Age }\end{array}$ & $\begin{array}{l}1.19 \\
1.89 \\
\end{array}$ & $\begin{array}{l}-0.67 ; 3.06 \\
-0.14 ; 3.93\end{array}$ & $\begin{array}{l}0.21 \\
0.07\end{array}$ & $\begin{array}{l}0.36 \\
0.22 \\
\end{array}$ \\
\hline \multicolumn{6}{|l|}{ Genetic Analyses $(\mathrm{N}=132)$} \\
\hline Genetic risk score, continuous & Age + HFF & 0.65 & $0.16 ; 1.14$ & 0.01 & 0.39 \\
\hline
\end{tabular}

\section{Discussion}

In this explorative study, we investigated sex-specific distributions of HIC in a population-based sample and identified relevantly associated factors from a large panel of markers. Overall, HIC was normally distributed with significantly lower values in women; none of the participants exceeded the threshold for severe hepatic iron overload. 
We revealed notable sex-specific associations of HIC with markers of body composition, glucose metabolism, and alcohol consumption.

\subsection{Distribution of HIC and Effect of Age}

The distribution of HIC in our sample was comparable to other studies. The SHIP study [17] reported median HIC values of $34.4 \mathrm{~s}^{-1}$, and UK Biobank [18] found mean values of $44.02 \mathrm{~s}^{-1}$ compared to our $40.7 \mathrm{~s}^{-1}$. When applying the cutoff from the SHIP study, $44.5 \%$ of the participants of the current study presented mild iron overload. As expected, this is a higher prevalence than that found in the SHIP study (17.4\%) and a slightly lower prevalence than that found in the UK Biobank study (51.5\%). We found higher values of HIC in men compared to women, which is coherent with results from the UK Biobank and SHIP studies $[17,18]$. Higher levels of HIC in men might be partly explained by higher levels of testosterone, since androgens are known to be regulators of hepcidin expression [19]. Besides, men had higher HFF levels than women, and HFF is substantially associated with HIC, as outlined below. Moreover, most women, before onset of menopause, regularly excrete iron through menstrual bleeding, leading to generally lower body iron. We found a strong correlation between age and HIC in women, suggesting a link to the onset of menopause. Our findings regarding the effect of age on HIC are supported by the study of Obrzut et al. [20], who examined considerably younger participants and reported distinctly lower HIC levels (mean: $28.7 \mathrm{~s}^{-1}$ ).

\subsection{Body Composition and Blood Lipid Markers}

We identified HFF as a main factor associated with HIC. This is in line with results from the UK Biobank [18] and MRI studies on patient samples [8,21]. In our study, the association was stronger in women than in men.

Furthermore, our results demonstrated that VAT is associated with HIC in women. This may be explained by the fact that the iron-regulating hormone hepcidin is expressed in abdominal adipose tissue in addition to the liver, which is the main site of synthesis [22]. Consequently, higher amounts of adipose tissue stimulate the HAMP gene and increase hepcidin production. This pathway is independent of diabetes status [22], which might explain the stability of VAT as a factor associated with HIC among all analyses.

Our procedure selected triglycerides as a relevant factor for both sexes. This finding is supported by the observation of Jehn et al. [23], who reported a significant increase in serum ferritin with increasing triglyceride levels. In addition, a study including only participants with iron overload due to hemochromatosis reported elevated triglyceride levels as well [24]. Related to this finding is the selection of lipid-lowering agents in women, which might serve as a proxy for underlying hypertriglyceridemia in this context.

In summary, our results indicated a relationship between abdominal adipose tissue and lipid profile with hepatic iron storage. This relationship was more pronounced in women.

\subsection{Genetic Effects}

The genetic risk score was frequently selected as a relevant factor associated with HIC. Weights of the respective single-nucleotide polymorphisms (SNPs) were notably different between men and women (Table S2), indicating sex-specific effects. Among the iron metabolism genes, the genetic variants rs1799945 and rs1800562 in HFE showed the strongest association with HIC in men and women, respectively. Both SNPs lead to hepatic iron overload due to decreased hepcidin levels $[25,26]$. These SNPs are additionally associated with ferritin and transferrin [27,28]. Moreover, variants rs855791 and rs4820268 in TMPRSS6 are known to be associated with iron traits including transferrin, serum iron, and ferritin [25,29], since TMPRSS6 modulates the transcription of hepcidin [29]. Furthermore, a mendelian randomization study that analyzed UK Biobank data revealed a causal relationship between central obesity and elevated HIC [25]. It is hypothesized that 
an interplay between genetics and dietary factors as well as cross-talk between liver and adipose tissue is responsible for the causal effect of abdominal obesity on HIC.

\subsection{Markers of Glucose Metabolism}

Several diabetes-related markers were selected to be relevantly associated with HIC, even after exclusion of participants with established T2DM. We found an association with $\mathrm{HIC}$ for prediabetes and $\mathrm{HbA1c}$ in men, which is in line with Britton et al. [10] who found an inverse correlation between HIC and HbA1c. On the other hand, the SHIP study [17] reported that $\mathrm{HbA1c}$ was not a relevant predictor of iron overload in their study. Recent findings from a subcohort of the aforementioned study showed a stronger association between serum ferritin and T2DM and an altered glucose metabolism even in the absence of pathologic iron overload, suggesting a combined effect of hepatic iron overload and ferritin [30]. The relationship between prediabetes and increased HIC is consistent with other studies that analyzed the association of diabetes status and serum ferritin levels $[13,31]$.

Our results regarding fasting glucose and HIC are conflicting since we found a positive association between HIC and fasting glucose in women but a negative association in men, whereas $2 \mathrm{~h}$ glucose only showed a positive association in men. Animal studies showed an increase in blood glucose levels in animals with iron overload, indicating that increased iron storage might be associated with altered glucose metabolism [32]. A mendelian randomization study that analyzed UK Biobank data revealed a potentially causal association of fasting glucose with increased HIC [25].

An association between iron and diabetes risk in hereditary iron metabolism disorders such as hemochromatosis is already established [33]. Even nonpathologically increased body iron stores are related with higher risks for the development of T2DM [32]. Haap et al. [34] found a positive association between HIC with T2DM and insulin resistance. Moreover, dysmetabolic iron overload syndrome (DIOS), defined as the presence of iron overload and insulin resistance, is frequently observed in patients with MetS [32]. Consequently, there seems to be an association between insulin resistance syndrome and iron overload [13]. Increased ROS are observed in iron deficiency as well as iron overload syndromes; ROS are known to induce beta cell damage and insulin resistance [1]. An overactivation of gluconeogenesis, leading to increased hepcidin expression, is discussed as a pathway, leading to iron accumulation and cell damage within the liver. This indicates an interplay between hepatic dysfunction, serum ferritin, and metabolic disorders. Our results therefore confirm and expand previous findings regarding the association of markers of glucose metabolism with HIC.

\subsection{Alcohol Consumption}

The link between alcohol consumption and HFF is already established [35]. Our results also show that a higher consumption of alcohol is associated with increased HIC, independent of HFF. These results are consistent with Whitfield et al. [36], who reported that even moderate alcohol consumption raises body iron stores. Furthermore, patients with alcoholic liver disease have been found to show alcohol-induced suppression of hepcidin. Alcohol induces hypoxia, which is known to reduce the expression of hepatic HAMP and therefore lead to decreased hepcidin levels [37].

\subsection{Renal Function Parameters and Diuretics}

The data-driven approach revealed uric acid as a relevant factor associated with HIC in men and women. Previous studies including healthy adults reported a positive correlation between serum ferritin and uric acid independent of gender and age [38]. Furthermore, another study reported a worsening of hepatic and renal functioning when simultaneous elevations in uric acid and serum ferritin levels were present [39]. Potential mechanisms of the association between iron overload with increased uric acid could be 
related to oxidative stress or insulin sensitivity. Additionally, our group previously found an association between increased uric acid and HFF [40].

Contrary to formerly reported positive relations between serum ferritin and proteinuria [41], we found a negative association between HIC and urine albumin in men when including participants with established diabetes in the analysis. The results might differ due to the heterogeneous study populations, since Kim et al. [41] excluded patients with diabetes from the analyses.

We found that diuretic use was associated with lower HIC with relatively large effect sizes. Diuretics are frequently prescribed in patients with renal diseases and one study described a high proportion of anemia in hemodialysis patients, which in turn was associated with increased inflammatory status [42]. Systemic inflammation leads to an upregulation of signal transducers and activators of transcription 3 (STAT3) and increases the synthesis of hepcidin followed by a decrease in iron levels [43]. This pathway is as a possible explanation for our findings, indicating a role of renal function markers in liver iron storage.

\subsection{Complete Blood Count}

The selection of erythrocytes as a relevant variable was stable among the different models for both sexes, relating increased levels of erythrocytes with decreased HIC. We speculate that an increase in erythrocyte levels mirrors the expansion of erythropoiesis due to an increased iron demand within the body. To sufficiently cover the demand, hepcidin expression is suppressed and iron stored within the liver is released [44]. Interestingly, hemoglobin, the iron-containing protein in erythrocytes, and hematocrit were not among the selected variables associated with HIC in our study, whereas the SHIP study [17] revealed mean corpuscular hemoglobin as the most predictive marker for HIC. Additionally, we demonstrated that the selection of thrombocytes was more frequent among women compared to men. Thrombocytopenia is associated with iron deficiency due to the increased risk for hemorrhages; another study reports a correlation between HIC and thrombocytes in patients with transfusion-related iron overload [45].

\subsection{Electrolyte Panel and Medication}

We identified potassium as a relevant marker in women associated with a decrease in HIC. Given that iron overload is associated with T2DM, this relationship is plausible since hypokalemia is associated with an increased risk for T2DM due to reduced insulin sensitivity [46]. However, diuretic use can also affect potassium balance and, as mentioned above, diuretic use was also found to be associated with HIC.

Additionally, we observed a negative association between sodium and HIC in women. Hyponatremia is frequently observed in cirrhotic patients and decreased serum levels correlate with the severity of cirrhosis [47]. Our results indicate that this association might already be visible in the non-pathological range.

The use of cardiovascular medication (ACE inhibitors in men, calcium antagonists in women) was found to be relevantly associated with decreased HIC. Associations of cardiovascular medication with serum ferritin have already been suggested [48], but conclusive findings about the effect of antihypertensive medication on iron metabolism are lacking. Results from animal studies suggest that a decrease in divalent metal transporter-1 (DMT-1) expression due to calcium antagonists may be responsible for a reduction in iron absorption [49].

\subsection{Strengths and Limitations}

Our study has unique strengths. The study sample from an established populationbased cohort was well-characterized, which enabled the analysis of a rich set of markers and risk factors. The assessment of HIC by MRI allowed for a precise quantification of both hepatic iron and fat content. Moreover, we applied appropriate statistical techniques to identify relevant associated factors and ensure the robustness and stability of our findings. 
Nevertheless, our study has several limitations which need to be addressed. Most importantly, we lacked data of serum indices of iron metabolism, such as ferritin and hepcidin. Further research on disentangling the association of circulating iron markers and markers of iron storage is necessary. To achieve this aim, follow-up studies investigating the molecular basis of the associations, as well as further characterization of the genetic effects in relation to hepcidin levels, need to be conducted. Moreover, the available dataset was limited to a relatively small size. Therefore, replication and extension of our findings in larger population-based cohorts are needed. One opportunity is the German National Cohort, a population-based study within Germany with MRI data on 30,000 participants, which would enable more intricate analyses with higher statistical power.

\section{Materials and Methods}

\subsection{Study Design and Participants}

The study sample consisted of participants from the cross-sectional KORA MRI study (KORA: "Cooperative Health Research in the Region of Augsburg"), nested within the KORA FF4 study ( $N=2279$, enrolled between 2013-2014). KORA FF4 is the second followup of the population-based KORA S4 cohort ( $\mathrm{N}=4261$, enrolled between 1999-2001). Overall, the study design, recruitment, and data collection of the KORA studies have been described in detail elsewhere [50]. The KORA MRI sub-study included 400 participants who underwent whole-body MRI, with a focus on assessing subclinical cardiometabolic diseases at different stages of impaired glucose metabolism [51]. Briefly, participants with a history of cardiovascular disease, older than 73 years, or with any contraindications to whole-body MRI were excluded. For the current analysis, a total of 47 participants had to be excluded due to missing hepatic iron measurements or covariables, yielding a final main sample size of 353 participants. The detailed participant flow is shown in Figure 5.

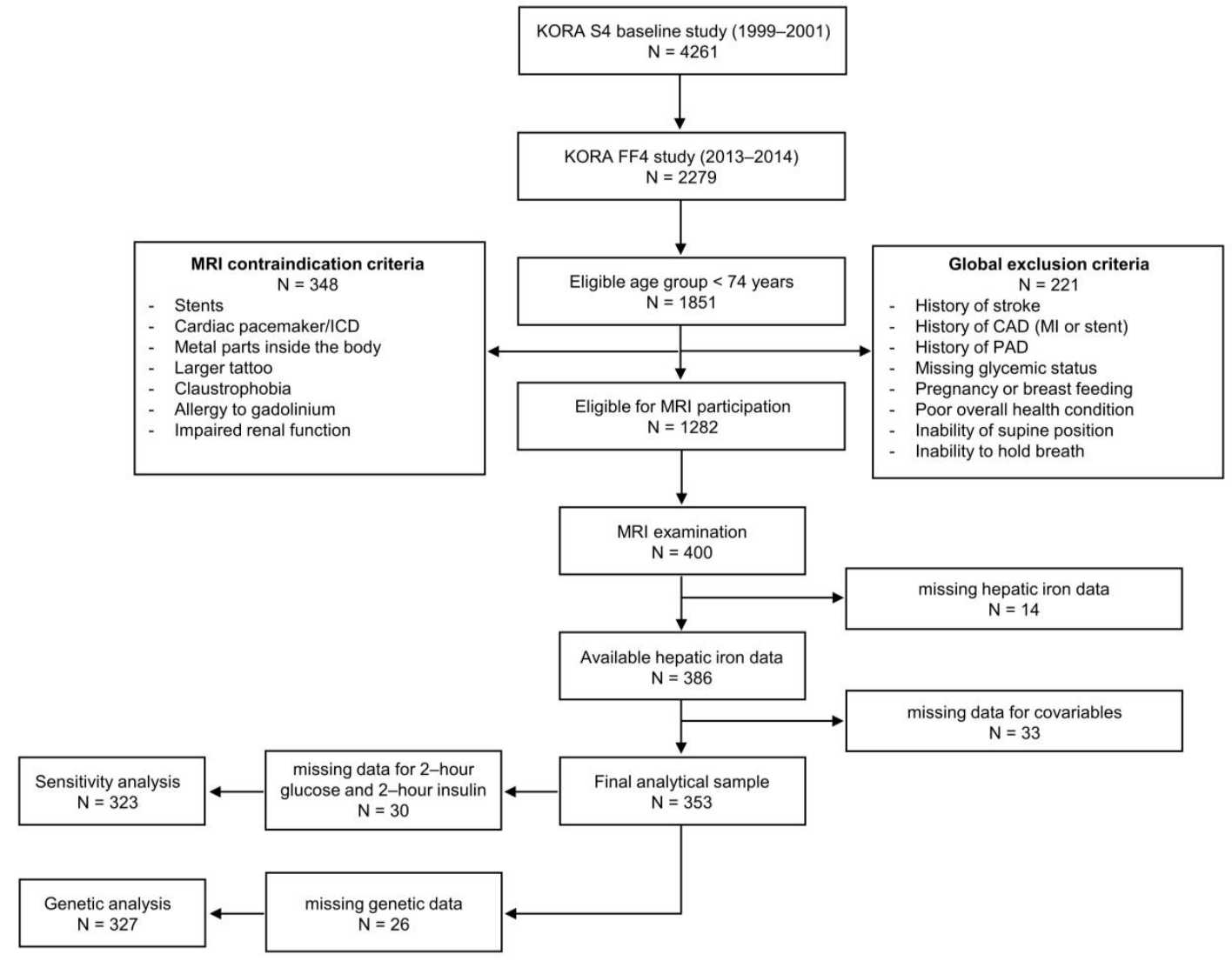

Figure 5. Participant flow chart. MRI, magnetic resonance imaging; CAD, coronary artery disease; MI, myocardial infarction; PAD, peripheral artery disease; ICD, implantable cardioverter defibrillator. 


\subsection{Outcome and Exposure Assessment}

\subsubsection{MRI Examination: Hepatic Iron and Fat Content}

MRI examinations were performed on a 3 Tesla MRI scanner (Magnetom Skyra; Siemens AG, Siemens Healthineers, Erlangen, Germany). The protocol was comprised of dedicated sequences for the respective body regions, as detailed elsewhere [51]. HIC was measured in the right and left hepatic lobe (segments VII and II, respectively) using single-voxel spectroscopy with a high-speed T2-corrected multi-echo (HISTO) technique, allowing for the simultaneous assessment of hepatic iron and hepatic fat [52]. Hepatic fat was obtained as HFF in percent and averaged over the left and right liver lobe. HIC was quantified as relaxation rate $1 / \mathrm{T}^{*}$ in s ${ }^{-1}$. The arithmetic mean averaged over the left and right liver lobe constitutes the main outcome of the present analysis.

\subsubsection{Covariates}

A set of health-related covariables was collected from all KORA FF4 participants at the study center in a standardized fashion. Briefly, the assessment was comprised of laboratory values, anthropometric measurements, information about medication intake, sociodemographic characteristics, and health behavior (e.g., smoking, physical activity). Data were collected and maintained by trained staff according to standardized protocols. A venous blood sample in fasted condition was drawn from each participant to determine laboratory values. The laboratory analysis included a standard complete blood count, information about blood lipids, glucose metabolism markers, renal function parameters, an electrolyte panel, and liver enzymes. Precise information and procedures are detailed in Table S1. Since $2 \mathrm{~h}$ insulin and $2 \mathrm{~h}$ glucose data were only available for participants without established T2DM, sensitivity analyses including these variables were performed on a smaller sample without participants with diagnosed T2DM.

Furthermore, VAT and subcutaneous adipose tissue (SAT) were measured by MRI using a three-dimensional in/opposed-phase VIBE-Dixon sequence from the femoral head to the diaphragm and cardiac apex, respectively. VAT and SAT were post-processed using an automated algorithm-driven procedure for segmentation [53] and are given in liter (L).

Genotyping was done with an Affymetrix Axiom Chip [54] and subsequent imputation was based on the Haplotype Reference Consortium (HRC) imputation panel r1.1, resulting in post-imputation probabilities (dosages) per allele.

\subsection{Statistical Analysis}

Descriptive statistics for continuous variables are presented as either arithmetic means and standard deviations (SDs) or medians and interquartile ranges (IQRs), where appropriate, and as counts and percentages for categorical variables. Differences between male and female participants were tested using $t$-tests, Mann-Whitney $U$ tests, or $\chi^{2}$ tests, respectively. Correlations between HIC and continuous exposure variables were determined by Spearman's rho correlation coefficient and corresponding $p$-values. Additionally, participants were classified according to presence of hepatic steatosis defined by a cutoff of HFF $\geq 5.6 \%$ [55]. All analyses were stratified by sex.

To identify relevant factors associated with HIC, LASSO regression was performed. LASSO is particularly suitable for this exploratory study as it constitutes a variable selection method able to extract the most strongly associated factors from a large set of potentially correlated variables [56]. LASSO achieves variable selection by applying a regularization process where regression coefficients of less-associated variables are shrunk towards zero by adding a penalty term, $\lambda$. To quantify the relative importance of the selected variables and assess model stability 1000 bootstrap samples were generated and the LASSO regression model was fitted on each one. The penalty term $\lambda$ was optimized for each bootstrap sample via 10 -fold cross-validation. The percentage of variable inclusion among the 1000 bootstrap samples was calculated to quantify the relative importance of each variable, and variables with inclusion frequencies $>20 \%$ were considered relevant [57]. Due to 
the regularization procedure LASSO coefficients are biased towards zero. Therefore, the calculation of confidence intervals and $p$-values is not straightforward.

To assess the strength of associations between covariables and HIC, unpenalized linear regression analyses adjusted for age and HFF were applied for every variable selected in LASSO regression. Results from unpenalized regression analyses are reported as unstandardized beta coefficients with corresponding confidence intervals, $p$-values, and adjusted $R^{2}$. Variables with a highly skewed distribution were log-transformed before regression analyses. To further assess model stability both penalized LASSO regressions and unpenalized regressions were run, excluding HFF as a covariate.

A genetic risk score was calculated to estimate the combined effect of selected SNPs on HIC. Relevant SNPs associated with markers of iron metabolism were identified by querying the GWAS Catalog (https:/ / www.ebi.ac.uk/gwas/, accessed on 4 August 2021). Further details on SNPs and corresponding genes are provided in Table S2. SNPs were then weighted by coefficients from sex-stratified univariate linear regressions against HIC (Table S2), multiplied by the respective allele dosage, and summed up. The continuous genetic risk score was then included in the variable selection procedure.

In this exploratory analysis $p$-values were not corrected for multiple testing and values less than 0.05 were considered to indicate statistical significance. All analyses were performed using $\mathrm{R}$ version 3.6.1.

\section{Conclusions}

Our results indicate sex-specific associations of MRI-derived HIC with several factors, specifically markers of glucose metabolism, renal function, body composition, alcohol intake, and genetic markers. Thus, our study extends previous knowledge of relevant HIC-related factors to a population-based sample. Further work is required to disentangle the complexity of pathways between disorders of iron homeostasis and pathologies.

Supplementary Materials: The following are available online at https:/ / www.mdpi.com/article/10 .3390 / metabo11120871/s1, Table S1: Description of variable assessment, Table S2: SNPs included in the genetic risk score, Table S3: Reference intervals of laboratory values, with corresponding mean, minimum, and maximum values in the study sample, Table S4: Men: Results from unpenalized linear regression analyses from sensitivity analysis. $\beta$ denotes the regression coefficient of the respective variable for outcome HIC. Adjusted $\mathrm{R}^{2}$ denotes the explained variance in HIC. Only variables with an inclusion frequency $>20 \%$ in the variable selection procedure are presented, Table S5: Women: Results from unpenalized linear regression analyses from sensitivity analysis. $\beta$ denotes the regression coefficient of the respective variable for outcome HIC. Adjusted $\mathrm{R}^{2}$ denotes the explained variance in HIC. Only variables with an inclusion frequency $>20 \%$ in the variable selection procedure are presented, Figure S1: Boxplots of HIC according to hepatic steatosis status by sex. The cutoff for hepatic steatosis was HFF $\geq 5.6 \%$, as defined by Schaapman et al. [55], Figure S2: Bar diagrams of results from the model, excluding HFF for (a) men and (b) women. Relevant variables were identified by variable selection through LASSO regression on 1000 bootstrap samples. On the y-axis: Inclusion frequency of the respective variable across 1000 bootstrap samples. Only variables with an inclusion frequency $>20 \%$ are presented, Figure S3: Bar diagrams of results from the sensitivity analysis, including HFF for (a) men and (b) women. Relevant variables were identified by variable selection through LASSO regression on 1000 bootstrap samples. On the y-axis: Inclusion frequency of the respective variable across 1000 bootstrap samples. Only variables with an inclusion frequency $>20 \%$ are presented, Figure S4: Bar diagrams of results from the sensitivity analysis, excluding HFF for (a) men and (b) women. Relevant variables were identified by variable selection through LASSO regression on 1000 bootstrap samples. On the y-axis: Inclusion frequency of the respective variable across 1000 bootstrap samples. Only variables with an inclusion frequency $>20 \%$ are presented [58-76].

Author Contributions: L.M. performed the statistical analyses, evaluated the results, and drafted the manuscript. F.B. and A.P. conceived and designed the KORA-MRI study. R.v.K., J.N., F.B. and C.L.S. collected the MRI data and analyzed the images. R.v.K., R.L., J.N., F.B. and C.L.S. contributed substantially to MRI data preparation and quality assurance. B.T., W.K., W.R. and A.P. 
contributed substantially to the collection, quality assurance, and data preparation of the biomarker measurements within KORA. R.v.K., R.L., J.F., J.N., B.T., W.K., W.R., F.B., C.L.S. and A.P. contributed substantially to the scientific content and interpretation of the results. S.R. conceived the study question and contributed to the statistical analyses, interpretation of the results, and drafting of the manuscript. S.R. had the primary responsibility for the final content. All authors have read and agreed to the published version of the manuscript.

Funding: This project has been financed in part through HGF Future Topic AMPro. The KORA study was initiated and financed by the Helmholtz Zentrum München-German Research Center for Environmental Health, which is funded by the German Federal Ministry of Education and Research $(\mathrm{BMBF})$ and the state of Bavaria. Furthermore, KORA research was supported within the Munich Center of Health Sciences (MC-Health), Ludwig-Maximilians-Universität, as part of L.M.Uinnovativ. The KORA MRI sub-study received funding by the German Research Foundation (DFG, Deutsche Forschungsgemeinschaft, BA 4233/4-1, http:/ / www.dfg.de/, accessed on 12 December 2021), the Centre for Diabetes Research (DZD e.V., Neuherberg, Germany), and the German Centre for Cardiovascular Disease Research (Berlin, Germany, grants 81X2600209 and 81X2600214). The KORA-MRI sub-study was supported by an unrestricted research grant from Siemens Healthcare. The funders had no role in the study design, data collection and analysis, decision to publish, or preparation of the manuscript.

Institutional Review Board Statement: The study was approved by the ethics committee of LudwigMaximilians-University Munich (498-12) and the Bavarian Chamber of Physicians (FF4: EC No. 06068); it was performed according to the Declaration of Helsinki.

Informed Consent Statement: Written informed consent was obtained from all subjects involved in the study.

Data Availability Statement: Restrictions apply to the availability of some or all of the data generated or analyzed during this study to preserve patient confidentiality or because they were used under license. The corresponding author will, on request, detail the restrictions and any conditions under which access to some data may be provided.

Acknowledgments: The authors are grateful for the participants who volunteered to provide the data. We thank the field workers, radiologists, interviewers, technicians, and computer assistants for their contributions to the collection of data.

Conflicts of Interest: The authors declare no conflict of interests.

\section{References}

1. Fleming, R.E.; Ponka, P. Iron Overload in Human Disease. N. Engl. J. Med. 2012, 366, 348-359. [CrossRef]

2. Papanikolaou, G.; Tzilianos, M.; Christakis, J.I.; Bogdanos, D.; Tsimirika, K.; Macfarlane, J.; Goldberg, Y.P.; Sakellaropoulos, N.; Ganz, T.; Nemeth, E. Hepcidin in iron overload disorders. Blood 2005, 105, 4103-4105. [CrossRef]

3. Pietrangelo, A. Iron and the liver. Liver Int. 2016, 36 (Suppl. 1), 116-123. [CrossRef] [PubMed]

4. Hernando, D.; Levin, Y.S.; Sirlin, C.B.; Reeder, S.B. Quantification of liver iron with MRI: State of the art and remaining challenges. J. Magn. Reson. Imaging 2014, 40, 1003-1021. [CrossRef] [PubMed]

5. Mehta, K.J.; Farnaud, S.J.; Sharp, P.A. Iron and liver fibrosis: Mechanistic and clinical aspects. World J. Gastroenterol. 2019, 25, 521-538. [CrossRef] [PubMed]

6. Mendler, M.-H.; Turlin, B.; Moirand, R.; Jouanolle, A.-M.; Sapey, T.; Guyader, D.; le Gall, J.-Y.; Brissot, P.; David, V.; Deugnier, Y. Insulin resistance-associated hepatic iron overload. Gastroenterology 1999, 117, 1155-1163. [CrossRef]

7. Seravalle, G.; Dell'Oro, R.; Quarti-Trevano, F.; Spaziani, D.; Bertoli, S.; Airoldi, F.; Mancia, G.; Grassi, G. Sympathetic Overactivation in Patients with Essential Hypertension and Hepatic Iron Overload. Hypertensionaha 2020, 76, 1444-1450. [CrossRef] [PubMed]

8. Karlsson, M.; Ekstedt, M.; Dahlström, N.; Forsgren, M.F.; Ignatova, S.; Norén, B.; Leinhard, O.D.; Kechagias, S.; Lundberg, P. Liver R2* is affected by both iron and fat: A dual biopsy-validated study of chronic liver disease. J. Magn. Reson. Imaging 2019, 50, 325-333. [CrossRef]

9. Radford-Smith, D.E.; Powell, E.E.; Powell, L.W. Haemochromatosis: A clinical update for the practising physician. Intern. Med. J. 2018, 48, 509-516. [CrossRef] [PubMed]

10. Britton, L.; Bridle, K.; Reiling, J.; Santrampurwala, N.; Wockner, L.; Ching, H.; Stuart, K.; Subramaniam, V.N.; Jeffrey, G.; Pierre, T.S.; et al. Hepatic iron concentration correlates with insulin sensitivity in nonalcoholic fatty liver disease. Hepatol. Commun. 2018, 2, 644-653. [CrossRef] 
11. Castiella, A.; Urreta, I.; Zapata, E.; Zubiaurre, L.; Alústiza, J.M.; Otazua, P.; Salvador, E.; Letamendi, G.; Arrizabalaga, B.; Rincón, M.L.; et al. Liver iron concentration in dysmetabolic hyperferritinemia: Results from a prospective cohort of 276 patients. Ann. Hepatol. 2020, 19, 31-35. [CrossRef] [PubMed]

12. Liu, Y.; Song, J.; Tian, H.; Chen, T.; Gao, Y.; Yu, H.; Zhang, X.; Ren, Y. Association of serum ferritin concentrations with prevalence of prediabetes, type 2 diabetes mellitus, and metabolic syndrome in a Chinese population from Sichuan. Int. J. Diabetes Dev. Ctries. 2015, 35, 522-528. [CrossRef]

13. Wrede, C.E.; Buettner, R.; Bollheimer, L.C.; Schölmerich, J.; Palitzsch, K.-D.; Hellerbrand, C. Association between serum ferritin and the insulin resistance syndrome in a representative population. Eur. J. Endocrinol. 2006, 154, 333-340. [CrossRef]

14. Daru, J.; Colman, K.; Stanworth, S.J.; De La Salle, B.; Wood, E.; Pasricha, S.-R. Serum ferritin as an indicator of iron status: What do we need to know? Am. J. Clin. Nutr. 2017, 106, 1634S-1639S. [CrossRef] [PubMed]

15. Ernst, O.; Sergent, G.; Bonvarlet, P.; Canva-Delcambre, V.; Paris, J.C.; L'Herminé, C. Hepatic iron overload: Diagnosis and quantification with MR imaging. Am. J. Roentgenol. 1997, 168, 1205-1208. [CrossRef] [PubMed]

16. Lawrence, S.P.; Caminer, S.J.; Yavorski, R.T.; Borosky, B.D.; Rak, K.M.; Merenich, J.A.; McDermott, M.T.; McNally, P.R. Correlation of Liver Density by Magnetic Resonance Imaging and Hepatic Iron Levels: A Noninvasive Means to Exclude Homozygous Hemochromatosis. J. Clin. Gastroenterol. 1996, 23, 113-117. [CrossRef] [PubMed]

17. Kühn, J.-P.; Meffert, P.; Heske, C.; Kromrey, M.-L.; Schmidt, C.O.; Mensel, B.; Völzke, H.; Lerch, M.M.; Hernando, D.; Mayerle, J.; et al. Prevalence of Fatty Liver Disease and Hepatic Iron Overload in a Northeastern German Population by Using Quantitative MR Imaging. Radiology 2017, 284, 706-716. [CrossRef] [PubMed]

18. McKay, A.; Wilman, H.; Dennis, A.; Kelly, M.; Gyngell, M.L.; Neubauer, S.; Bell, J.D.; Banerjee, R.; Thomas, E.L. Measurement of liver iron by magnetic resonance imaging in the UK Biobank population. PLoS ONE 2018, 13, e0209340. [CrossRef]

19. Guo, W.; Bachman, E.; Li, M.; Roy, C.N.; Blusztajn, J.; Wong, S.; Chan, S.Y.; Serra, C.; Jasuja, R.; Travison, T.G.; et al. Testosterone administration inhibits hepcidin transcription and is associated with increased iron incorporation into red blood cells. Aging Cell 2013, 12, 280-291. [CrossRef] [PubMed]

20. Obrzut, M.; Atamaniuk, V.; Glaser, K.J.; Chen, J.; Ehman, R.L.; Obrzut, B.; Cholewa, M.; Gutkowski, K. Value of liver iron concentration in healthy volunteers assessed by MRI. Sci. Rep. 2020, 10, 17887. [CrossRef]

21. Bashir, M.R.; Wolfson, T.; Gamst, A.C.; Fowler, K.J.; Ohliger, M.; Shah, S.N.; Alazraki, A.; Trout, A.T.; Behling, C.; Allende, D.S.; et al. Hepatic R2* is more strongly associated with proton density fat fraction than histologic liver iron scores in patients with nonalcoholic fatty liver disease. J. Magn. Reson. Imaging 2019, 49, 1456-1466. [CrossRef]

22. Bekri, S.; Gual, P.; Anty, R.; Luciani, N.; Dahman, M.; Ramesh, B.; Iannelli, A.; Staccini-Myx, A.; Casanova, D.; Ben Amor, I.; et al. Increased Adipose Tissue Expression of Hepcidin in Severe Obesity Is Independent from Diabetes and NASH. Gastroenterology 2006, 131, 788-796. [CrossRef]

23. Jehn, M.; Clark, J.M.; Guallar, E. Serum Ferritin and Risk of the Metabolic Syndrome in U.S. Adults. Diabetes Care 2004, 27, 2422-2428. [CrossRef]

24. Seeßle, J.; Gan-Schreier, H.; Kirchner, M.; Stremmel, W.; Chamulitrat, W.; Merle, U. Plasma Lipidome, PNPLA3 polymorphism and hepatic steatosis in hereditary hemochromatosis. BMC Gastroenterol. 2020, 20, 230. [CrossRef]

25. Wilman, H.R.; Parisinos, C.A.; Atabaki-Pasdar, N.; Kelly, M.; Thomas, E.L.; Neubauer, S.; Mahajan, A.; Hingorani, A.D.; Patel, R.S.; Hemingway, H.; et al. Genetic studies of abdominal MRI data identify genes regulating hepcidin as major determinants of liver iron concentration. J. Hepatol. 2019, 71, 594-602. [CrossRef] [PubMed]

26. Yuan, S.; Carter, P.; Vithayathil, M.; Kar, S.P.; Giovannucci, E.; Mason, A.M.; Burgess, S.; Larsson, S.C. Iron Status and Cancer Risk in UK Biobank: A Two-Sample Mendelian Randomization Study. Nutrients 2020, 12, 526. [CrossRef] [PubMed]

27. Meidtner, K.; Podmore, C.; Kröger, J.; van der Schouw, Y.T.; Bendinelli, B.; Agnoli, C.; Arriola, L.; Barricarte, A.; Boeing, H.; Cross, A.J.; et al. Interaction of Dietary and Genetic Factors Influencing Body Iron Status and Risk of Type 2 Diabetes Within the EPIC-InterAct Study. Diabetes Care 2017, 41, 277-285. [CrossRef] [PubMed]

28. Raffield, L.M.; Louie, T.; Sofer, T.; Jain, D.; Ipp, E.; Taylor, K.D.; Papanicolaou, G.J.; Aviles-Santa, M.L.; Lange, L.A.; Laurie, C.C.; et al. Genome-wide association study of iron traits and relation to diabetes in the Hispanic Community Health Study/Study of Latinos (HCHS/SOL): Potential genomic intersection of iron and glucose regulation? Hum. Mol. Genet. 2017, 26, 1966-1978. [CrossRef]

29. De Tayrac, M.; Roth, M.-P.; Jouanolle, A.-M.; Coppin, H.; le Gac, G.; Piperno, A.; Férec, C.; Pelucchi, S.; Scotet, V.; Bardou-Jacquet, E.; et al. Genome-wide association study identifies TF as a significant modifier gene of iron metabolism in HFE hemochromatosis. J. Hepatol. 2015, 62, 664-672. [CrossRef]

30. Pitchika, A.; Kühn, J.; Schipf, S.; Nauck, M.; Dörr, M.; Lerch, M.M.; Kromrey, M.; Felix, S.B.; Markus, M.R.P.; Rathmann, W.; et al. Hepatic steatosis and hepatic iron overload modify the association of iron markers with glucose metabolism disorders and metabolic syndrome. Liver Int. 2021, 41, 1841-1852. [CrossRef]

31. Sharifi, F.; Nasab, N.M.; Zadeh, H.J. Elevated serum ferritin concentrations in prediabetic subjects. Diabetes Vasc. Dis. Res. 2008, 5, 15-18. [CrossRef] [PubMed]

32. Fillebeen, C.; Lam, N.H.; Chow, S.; Botta, A.; Sweeney, G.; Pantopoulos, K. Regulatory Connections between Iron and Glucose Metabolism. Int. J. Mol. Sci. 2020, 21, 7773. [CrossRef]

33. Simcox, J.A.; McClain, D.A. Iron and Diabetes Risk. Cell Metab. 2013, 17, 329-341. [CrossRef] [PubMed] 
34. Haap, M.; Machann, J.; Von Friedeburg, C.; Schick, F.; Stefan, N.; Schwenzer, N.F.; Fritsche, A.; Häring, H.U.; Thamer, C. Insulin Sensitivity and Liver Fat: Role of Iron Load. J. Clin. Endocrinol. Metab. 2011, 96, E958-E961. [CrossRef] [PubMed]

35. Bayerl, C.; Lorbeer, R.; Heier, M.; Meisinger, C.; Rospleszcz, S.; Schafnitzel, A.; Patscheider, H.; Auweter, S.; Peters, A.; ErtlWagner, B.; et al. Alcohol consumption, but not smoking is associated with higher MR-derived liver fat in an asymptomatic study population. PLoS ONE 2018, 13, e0192448. [CrossRef] [PubMed]

36. Whitfield, J.B.; Zhu, G.; Heath, A.C.; Powell, L.W.; Martin, N.G. Effects of alcohol consumption on indices of iron stores and of iron stores on alcohol intake markers. Alcohol. Clin. Exp. Res. 2001, 25, 1037-1045. [CrossRef]

37. Bridle, K.R.; Cheung, T.-K.; Murphy, T.L.; Walters, M.M.; Anderson, G.J.; Crawford, D.H.G.; Fletcher, L.M. Hepcidin Is Downregulated in Alcoholic Liver Injury: Implications for the Pathogenesis of Alcoholic Liver Disease. Alcohol. Clin. Exp. Res. 2006, 30, 106-112. [CrossRef]

38. Li, X.; He, T.; Yu, K.; Lu, Q.; Alkasir, R.; Guo, G.; Xue, Y. Markers of Iron Status Are Associated with Risk of Hyperuricemia among Chinese Adults: Nationwide Population-Based Study. Nutrients 2018, 10, 191. [CrossRef]

39. Mainous, A.G.; Knoll, M.E.; Everett, C.J.; Matheson, E.M.; Hulihan, M.M.; Grant, A.M. Uric Acid as a Potential Cue to Screen for Iron Overload. J. Am. Board Fam. Med. 2011, 24, 415-421. [CrossRef]

40. Rospleszcz, S.; Dermyshi, D.; Müller-Peltzer, K.; Strauch, K.; Bamberg, F.; Peters, A. Association of serum uric acid with visceral, subcutaneous and hepatic fat quantified by magnetic resonance imaging. Sci. Rep. 2020, 10, 442. [CrossRef] [PubMed]

41. Kim, B.J.; Kim, B.S.; Kang, J.H. The association between serum ferritin level, microalbuminuria and non-alcoholic fatty liver disease in non-diabetic, non-hypertensive men. Clin. Exp. Hypertens. 2013, 36, 380-385. [CrossRef]

42. Małyszko, J.; Koc-Żórawska, E.; Levin-Iaina, N.; Małyszko, J.; Koźmiński, P.; Kobus, G.; Myśliwiec, M. New parameters in iron metabolism and functional iron deficiency in patients on maintenance hemodialysis. Pol. Arch. Intern. Med. Wewn 2012, 122, 537-542. [CrossRef]

43. Pietrangelo, A.; Dierssen, U.; Valli, L.; Garuti, C.; Rump, A.; Corradini, E.; Ernst, M.; Klein, C.; Trautwein, C. STAT3 Is Required for IL-6-gp130-Dependent Activation of Hepcidin In Vivo. Gastroenterology 2007, 132, 294-300. [CrossRef]

44. Muckenthaler, M.U.; Rivella, S.; Hentze, M.W.; Galy, B. A Red Carpet for Iron Metabolism. Cell 2017, 168, 344-361. [CrossRef]

45. Cheong, J.-W.; Kim, H.-J.; Lee, K.-H.; Yoon, S.-S.; Lee, J.H.; Park, H.-S.; Kim, H.Y.; Shim, H.; Seong, C.-M.; Kim, C.S.; et al. Deferasirox improves hematologic and hepatic function with effective reduction of serum ferritin and liver iron concentration in transfusional iron overload patients with myelodysplastic syndrome or aplastic anemia. Transfusion 2013, 54, $1542-1551$. [CrossRef] [PubMed]

46. Chatterjee, R.; Yeh, H.-C.; Edelman, D.; Brancati, F. Potassium and risk of Type 2 diabetes. Expert Rev. Endocrinol. Metab. 2011, 6, 665-672. [CrossRef] [PubMed]

47. Angeli, P.; Wong, F.; Watson, H.; Ginès, P. CAPPS Investigators Hyponatremia in cirrhosis: Results of a patient population survey. Hepatology 2006, 44, 1535-1542. [CrossRef] [PubMed]

48. Mainous, A.G.; Weinberg, E.D.; Diaz, V.A.; Johnson, S.P.; Hulihan, M.M.; Grant, A.M. Calcium channel blocker use and serum ferritin in adults with hypertension. Biometals 2012, 25, 563-568. [CrossRef]

49. Zhang, Y.; Zhao, X.; Chang, Y.; Zhang, Y.; Chu, X.; Zhang, X.; Liu, Z.; Guo, H.; Wang, N.; Gao, Y.; et al. Calcium channel blockers ameliorate iron overload-associated hepatic fibrosis by altering iron transport and stellate cell apoptosis. Toxicol. Appl. Pharmacol. 2016, 301, 50-60. [CrossRef]

50. Holle, R.; Happich, M.; Löwel, H.; Wichmann, H.E. KORA—A Research Platform for Population Based Health Research. Das Gesundheitswesen 2005, 67, 19-25. [CrossRef]

51. Bamberg, F.; Hetterich, H.; Rospleszcz, S.; Lorbeer, R.; Auweter, S.D.; Schlett, C.L.; Schafnitzel, A.; Bayerl, C.; Schindler, A.; Saam, T.; et al. Subclinical Disease Burden as Assessed by Whole-Body MRI in Subjects With Prediabetes, Subjects With Diabetes, and Normal Control Subjects From the General Population: The KORA-MRI Study. Diabetes 2016, 66, 158-169. [CrossRef] [PubMed]

52. Hetterich, H.; Bayerl, C.; Peters, A.; Heier, M.; Linkohr, B.; Meisinger, C.; Auweter, S.; Kannengießer, S.A.R.; Kramer, H.; Ertl-Wagner, B.; et al. Feasibility of a three-step magnetic resonance imaging approach for the assessment of hepatic steatosis in an asymptomatic study population. Eur. Radiol. 2015, 26, 1895-1904. [CrossRef] [PubMed]

53. Storz, C.; Heber, S.D.; Rospleszcz, S.; Machann, J.; Sellner, S.; Nikolaou, K.; Lorbeer, R.; Gatidis, S.; Elser, S.; Peters, A.; et al. The role of visceral and subcutaneous adipose tissue measurements and their ratio by magnetic resonance imaging in subjects with prediabetes, diabetes and healthy controls from a general population without cardiovascular disease. Br. J. Radiol. 2018, 91, 20170808. [CrossRef] [PubMed]

54. Suhre, K.; Arnold, M.; Bhagwat, A.M.; Cotton, R.J.; Engelke, R.; Raffler, J.; Sarwath, H.; Thareja, G.; Wahl, A.; DeLisle, R.K.; et al. Connecting genetic risk to disease end points through the human blood plasma proteome. Nat. Commun. $2017,8,14357$. [CrossRef] [PubMed]

55. Schaapman, J.J.; Tushuizen, M.E.; Coenraad, M.J.; Lamb, H.J. Multiparametric MRI in Patients with Nonalcoholic Fatty Liver Disease. J. Magn. Reson. Imaging 2021, 53, 1623-1631. [CrossRef] [PubMed]

56. Tibshirani, R. Regression Shrinkage and Selection Via the Lasso. J. R. Stat. Soc. Ser. B 1996, 58, 267-288. [CrossRef]

57. De Bin, R.; Janitza, S.; Sauerbrei, W.; Boulesteix, A.-L. Subsampling versus bootstrapping in resampling-based model selection for multivariable regression. Biometrics 2016, 72, 272-280. [CrossRef] [PubMed] 
58. Rabel, M.; Meisinger, C.; Peters, A.; Holle, R.; Laxy, M. The longitudinal association between change in physical activity, weight, and health-related quality of life: Results from the population-based KORA S4/F4/FF4 cohort study. PLoS ONE 2017, 12, e0185205. [CrossRef]

59. Teuner, C.M.; Menn, P.; Heier, M.; Holle, R.; John, J.; Wolfenstetter, S.B. Impact of BMI and BMI change on future drug expenditures in adults: Results from the MONICA/KORA cohort study. BMC Health Serv. Res. 2013, 13, 424. [CrossRef]

60. McLaren, C.E.; Garner, C.P.; Constantine, C.C.; McLachlan, S.; Vulpe, C.D.; Snively, B.M.; Gordeuk, V.R.; Nickerson, D.A.; Cook, J.D.; Leiendecker-Foster, C.; et al. Genome-Wide Association Study Identifies Genetic Loci Associated with Iron Deficiency. PLoS ONE 2011, 6, e17390. [CrossRef]

61. Liao, M.; Shi, J.; Huang, L.; Gao, Y.; Tan, A.; Wu, C.; Lü, Z.; Yang, X.; Zhang, S.; Hu, Y.; et al. Genome-Wide Association Study Identifies Variants in PMS1 Associated with Serum Ferritin in a Chinese Population. PLoS ONE 2014, 9, e105844. [CrossRef] [PubMed]

62. He, M.; Workalemahu, T.; Manson, J.E.; Hu, F.B.; Qi, L. Genetic Determinants for Body Iron Store and Type 2 Diabetes Risk in US Men and Women. PLoS ONE 2012, 7, e40919. [CrossRef]

63. Traglia, M.; Girelli, D.; Biino, G.; Campostrini, N.; Corbella, M.; Sala, C.; Masciullo, C.; Viganò, F.; Buetti, I.; Pistis, G.; et al. Association of HFE and TMPRSS6 genetic variants with iron and erythrocyte parameters is only in part dependent on serum hepcidin concentrations. J. Med. Genet. 2011, 48, 629-634. [CrossRef]

64. Oexle, K.; Ried, J.S.; Hicks, A.A.; Tanaka, T.; Hayward, C.; Bruegel, M.; Gögele, M.; Lichtner, P.; Müller-Myhsok, B.; Döring, A.; et al. Novel association to the proprotein convertase PCSK7 gene locus revealed by analysing soluble transferrin receptor (sTfR) levels. Hum. Mol. Genet. 2010, 20, 1042-1047. [CrossRef]

65. Nai, A.; Pagani, A.; Silvestri, L.; Campostrini, N.; Corbella, M.; Girelli, M.; Traglia, M.; Toniolo, D.; Camaschella, C. TMPRSS6 rs855791 modulates hepcidin transcription in vitro and serum hepcidin levels in normal individuals. Blood 2011, 118, 4459-4462. [CrossRef]

66. Gichohi-Wainaina, W.N.; Towers, G.W.; Swinkels, R.W.; Zimmermann, M.B.; Feskens, E.J.; Melse-Boonstra, A. Inter-ethnic differences in genetic variants within the transmembrane protease, serine 6 (TMPRSS6) gene associated with iron status indicators: A systematic review with meta-analyses. Genes Nutr. 2014, 10, 442. [CrossRef] [PubMed]

67. McLaren, C.E.; McLachlan, S.; Garner, C.P.; Vulpe, C.; Gordeuk, V.R.; Eckfeldt, J.H.; Adams, P.C.; Acton, R.T.; Murray, J.; Leiendecker-Foster, C.; et al. Associations between Single Nucleotide Polymorphisms in Iron-Related Genes and Iron Status in Multiethnic Populations. PLoS ONE 2012, 7, e38339. [CrossRef]

68. Hotta, K.; Yoneda, M.; Hyogo, H.; Ochi, H.; Mizusawa, S.; Ueno, T.; Chayama, K.; Nakajima, A.; Nakao, K.; Sekine, A. Association of the rs738409 polymorphism in PNPLA3 with liver damage and the development of nonalcoholic fatty liver disease. BMC Med. Genet. 2010, 11, 172. [CrossRef] [PubMed]

69. Kohse, K.P. Taschenlehrbuch Klinische Chemie und Hämatologie, 9th ed.; Thieme: Stuttgart, Germany, 2019.

70. Hahn, J.M. Checkliste Innere Medizin, 5th ed.; Thieme: Stuttgart, Germany, 2007.

71. Arbeitsgemeinschaft der Wissenschaftlichen Medizinischen Fachgesellschaften (AWMF)- Ständige Kommission Leitlinien. AWMF-Regelwerk “Nationale Versorgungsleitlinie Typ-2-Diabetes”. Available online: https://dev.leitlinien.de/themen/ diabetes/archiv/pdf/diabetes-fusskomplikationen/dm2-fuss-kurz-2-0.pdf (accessed on 12 August 2020).

72. Levey, A.S.; Stevens, L.A.; Schmid, C.H.; Zhang, Y.L.; Castro, A.F., 3rd; Feldman, H.I.; Kusek, J.W.; Eggers, P.; Van Lente, F.; Greene, T.; et al. A New Equation to Estimate Glomerular Filtration Rate. Ann. Intern. Med. 2009, 150, 604-612. [CrossRef]

73. Charité. Albumin. Available online: https://www.charite.de/fileadmin/user_upload/microsites/m_cc05/ilp/referenzdb/28 820.htm (accessed on 13 June 2021).

74. Charité. Kreatinin. Available online: https://www.charite.de/fileadmin/user_upload/microsites/m_cc05/ilp/referenzdb/30 738.htm (accessed on 13 June 2021).

75. Robert-Koch-Institut. Wie Wird der Vitamin-D-Status Bestimmt und Beurteilt? Available online: https://www.rki.de/ SharedDocs/FAQ/Vitamin_D/FAQ07.html (accessed on 13 June 2021).

76. Berlin, I. Troponin T High Sensitive (TroponinThs). Available online: https://www.imd-berlin.de/fachinformationen/ diagnostikinformationen/troponin-t-high-sensitive-troponinths (accessed on 13 June 2021). 